\title{
Synthetic Applications of Intramolecular Aza-Wittig Reaction for the Preparation of Heterocyclic Compounds
}

\author{
Francisco Palacios*, Domitila Aparicio, Gloria Rubiales, Concepción Alonso and Jesús M. de los \\ Santos
}

Departamento de Química Orgánica I, Facultad de Farmacia, Universidad del País Vasco. Apartado 450, 01080, SPAIN.

\begin{abstract}
A review focused on recent advances in intramolecular aza-Wittig reaction of phosphazenes with several carbonyl or analogous compounds is reported. Phosphazenes afford intramolecular aza-Wittig reaction with different groups within the molecule as aldehydes, ketones, esters, thioesters, amides, anhydrides and sulfimides. One of the most important applications of this reaction is the synthesis of a wide range of heterocyclic compounds, ranging from simple monocyclic compounds to complex polycyclic and macrocyclic systems.
\end{abstract}

\section{INTRODUCTION}

In 1919, Staudinger and Meyers prepared $\mathrm{PhN}=\mathrm{PPh}_{3}$, the first example of an aza-Wittig reagent [1], the nitrogen analogue of a Wittig reagent (Scheme 1). Although aza-Wittig reagents $\left(\lambda^{5}\right.$-phosphazenes, iminophosphoranes, phosphine imines) were first prepared at the beginning of past century, it was not till Wittig's work more than 30 years later that the reaction became accepted practice.

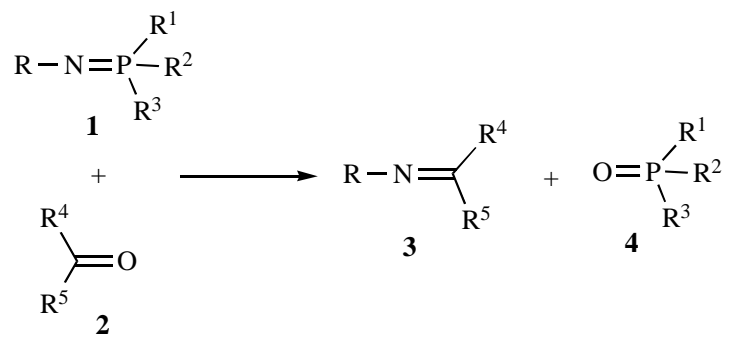

Scheme 1 .

Since then, the Wittig and aza-Wittig reactions have undergone tremendous development and have become a powerful tool in organic synthetic strategies directed towards the construction of nitrogen-containing heterocycles, mainly because the reaction is conducted in neutral solvents in the absence of catalysts, generally at mild reflux temperatures, and usually results in high yields.

Special interest has been focused on those aza-Wittig reactions of compounds 5 (Scheme 2 ) where both phosphazene moiety and carbon-oxygen double bond $(\mathrm{C}=\mathrm{O})$ (aldehydes, ketones, esters, amides, anhydrides...), or heteroatom-oxygen double bond $(\mathrm{S}=\mathrm{O})$ (sulfoxides...) are found within one molecule. This strategy involving intramolecular aza-Wittig reactions allows a method for the preparation of five- to different size heterocyclic compounds $\mathbf{6}$ in very mild reaction conditions (Scheme 2).

*Address correspondence to this author at the Departamento de Química Orgánica I, Facultad de Farmacia, Universidad del País Vasco. Apartado 450, 01080, SPAIN; Tel: ---_---_---; Fax: ---_-_----; E-mail:

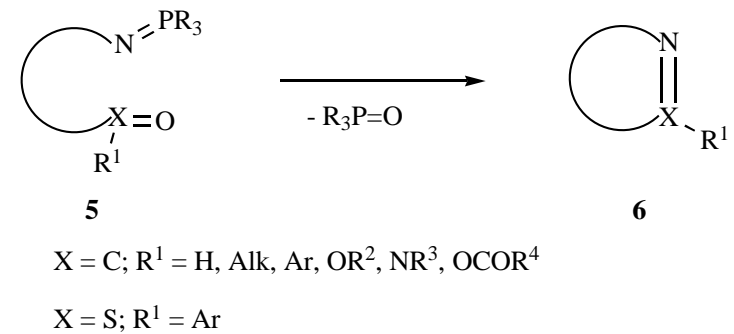

Scheme 2.

The reactivity of functionalized $\lambda^{5}$-phosphazenes varies in several factors depending on substituents at the carbonyl group or at the phosphorus atom of the phosphazene moiety. Aldehydes and ketones react better than other carbonyl derivatives (esters, amides) with phosphazene linkage, however, even amides and esters can undergo intramolecular reaction despite their low reactivity. On the other hand, substitution on the phosphorus atom in phosphazene moiety is also important. It is noteworthy that compounds derived from $\mathrm{PPh}_{2} \mathrm{Me}, \mathrm{PPhMe}_{2}, \mathrm{PMe}_{3}$ are more reactive than the triphenyl-counterpart since the electron-donating methyl group(s) decreases the positive charge on the phosphorus atom and concomitantly increases the negative charge on the nitrogen atom or that $\mathrm{P}(\mathrm{OR})_{3}$ derivatives are less reactive [2]. The most commonly used substituted phosphorus group, triphenylphosphazene, may then be replaced by other trisubstituted phosphazene groups with a consequent increase or decrease in the nucleophilicity of the phosphazene moiety and/or other desired effects affecting reaction rates as steric effects.

Numerous research papers and several reviews [3] have appeared describing the general use of $\lambda^{5}$-phosphazenes as reagents and intermediates in organic synthesis. The aim of this review is thoroughly cover exhaustively the work done, mainly in the two last decades, by the use of this methodology as well as the revision of heterocycles prepared, among them heterocyclic natural products and others, and the work has been classified taking into account the carbonyl group involved in the intramolecular key process. 


\section{PHOSPHAZENES DERIVED FROM ALDEHYDES}

Functionalized phosphazenes containing an aldehyde group are excellent starting material for the formation of $\mathrm{C}=\mathrm{N}$ double bond of heterocyclic systems [3h].

\subsection{Synthesis of Six-Membered Ring Systems}

Aza-Wittig reaction of phosphazenes has been successfully used for an elegant synthesis of six-membered nitrogen heterocycles with rigorous control of various asymmetric centers. For example, piperidine systems $9(\mathrm{R}=\mathrm{H})$, precursors in the synthesis of polyhydroxylated nitrogen heterocycles such as (-)-adenophorine, 1-epi-adenophorine as well as hydrophobically modified deoxynojirimycin (DNJ) variants, have been recently synthesized through the Staudinger/azaWittig sequence as shown in Scheme 3 [4].

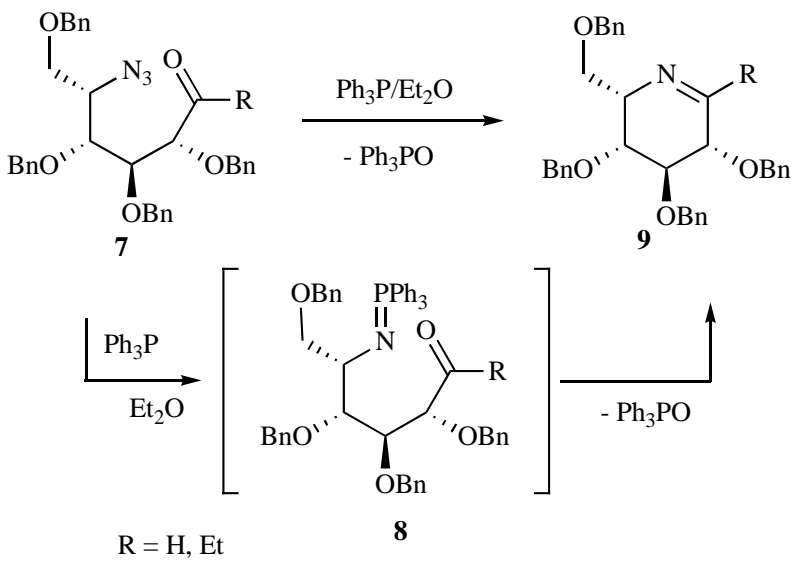

Scheme 3 .

By combining a Staudinger/intramolecular aza-Wittig and an Ugi three-component reaction (SAWU-3CR), the construction of piperidine-based bisamides has been recently reported [5]. The preparation of these functionalized piperidine-based bisamides 13 starts with reaction of trimethylphosphine with azido aldehydes 10. At this stage, the intermediate imine 12 was brought to $-78^{\circ} \mathrm{C}$ upon which carboxylic acid or amino acid and alkyl isocyanide were added to afford SAWU-3CR product $\mathbf{1 3}$ as a single diastereoisomer (Scheme 4).

In a similar fashion, the intermediate imine $\mathbf{1 5}$, formed by Staudinger/aza-Wittig reaction of azido aldehyde 14, was condensed with carboxylic and alkyl isocyanides to give the morpholine-based bisamides $\mathbf{1 6}$ (Scheme 5). The versatility of this procedure was demonstrated in the preparation of a small library of diverse, chiral and enantiomerically pure functionalized piperidines and morpholines [5].

Functionalized phosphazenes derived from aldehydes can also be used for the preparation of pyridine ring in polycyclic systems. 1-Hydroxypyrazolo[3,4-c]isoquinolines 20 have been prepared through the tandem Staudinger/intramolecular aza-Wittig reaction of 4-azido-5-aryl-substituted 1-benzyloxypyrazole 18, obtained from pyrazole 17 (Scheme 6) [6]. The pyridine ring of pyrazoloisoquinolines $\mathbf{2 0}$ was created via cyclization of a formyl group in a 2-formylphenylsubstituent at $C-5$ with a phosphazene group installed at $C-4$ of 1-benzyloxypyrazole obtained from Staudinger reaction of 18 with tributylphosphine.

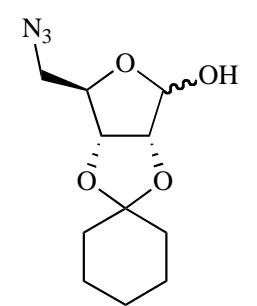

10

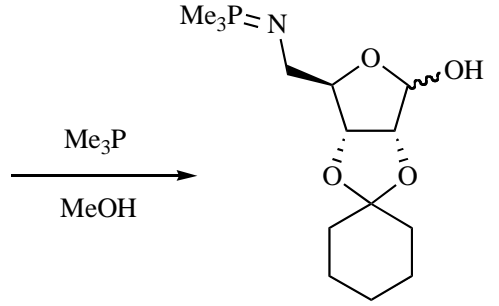

11<smiles>[R]C(=O)N1C[C@H](O)[C@H]2OC3(CCCCC3)O[C@H]2[C@@H]1C(=O)N[Y1](C)C(=O)O</smiles><smiles>[Te][Pb]=[Pt]</smiles><smiles>O[C@H]1CN=C[C@@H]2OC3(CCCCC3)O[C@H]12</smiles>

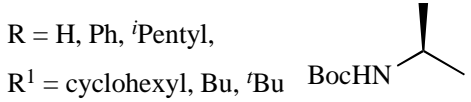

Scheme 4.

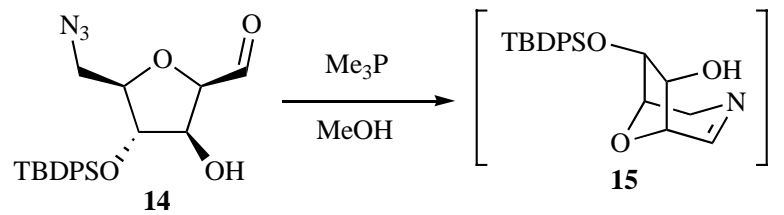
14

15

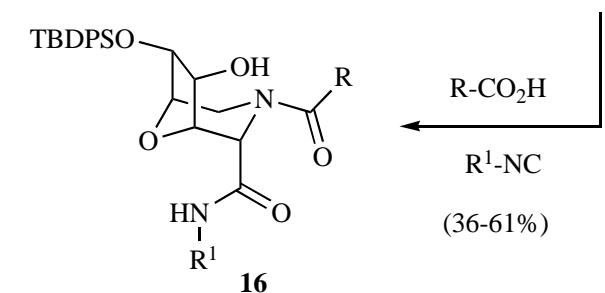

$\mathrm{R}=\mathrm{H}, \mathrm{Ph},{ }^{i}$ Pentyl

$\mathrm{R}^{1}=$ cyclohexyl, ${ }^{\mathrm{t}} \mathrm{Bu}$

Scheme 5.

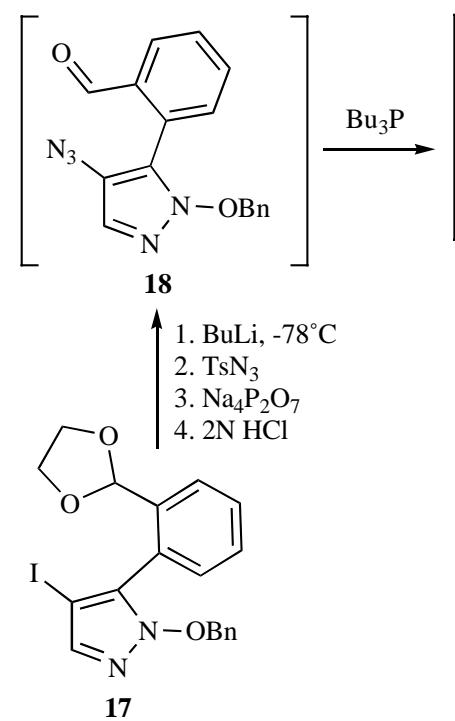<smiles>CC(C)C=Nc1cnn(O)c1-c1ccccc1C=O</smiles>

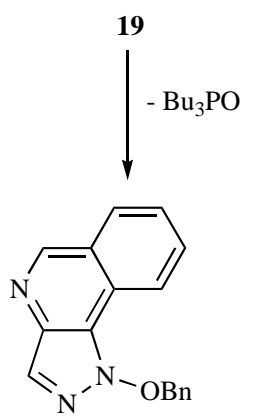

$20(72 \%)$

Scheme 6. 


\subsection{Synthesis of Seven-Membered Ring Systems}

Synthetic applications of aza-Wittig reaction of phosphazenes containing an aldehyde group are not restricted to the preparation of six-membered heterocycles, and for example Yadav et al. [7] have developed the synthesis of the optically active $(3 S, 4 S)$-hexahydroazepine core of balanol and ophiocordin by ring expansion to the seven-membered azepine through intramolecular aza-Wittig process. Azido aldehyde 22, obtained by removal of tert-butyl ether protecting group in tetrahydropyrane 21, was treated with triphenylphosphine in toluene at reflux and the resulting imine $\mathbf{2 4}$ was reduced with $\mathrm{NaBH}_{4}$ in methanol to yield sevenmembered azepine $\mathbf{2 5}$ in $\mathbf{7 5 \%}$ yield (Scheme 7).

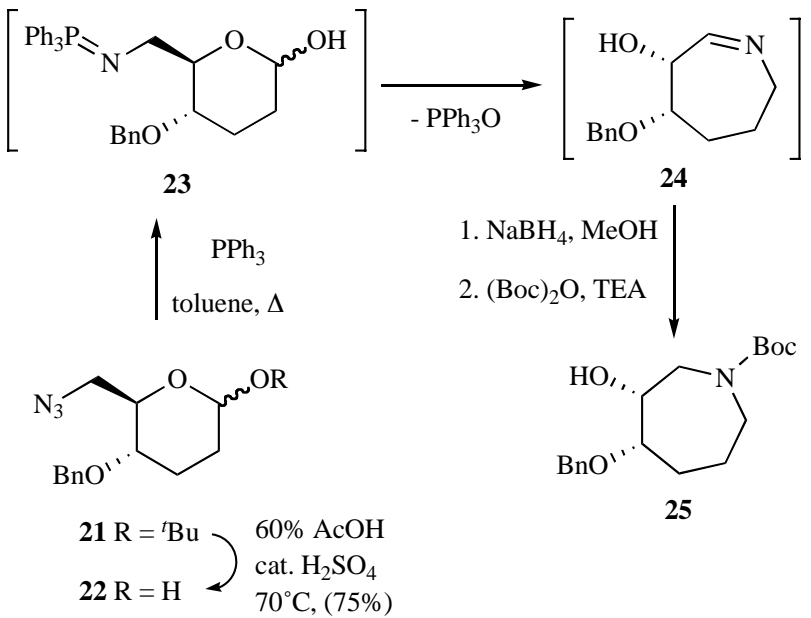

\section{Scheme 7.}

Intramolecular aza-Wittig reaction with aldehyde function allowed the stereocontrolled total synthesis of the polycyclic Stemona alkaloid, (-)-stemospironine (28) [8]. The

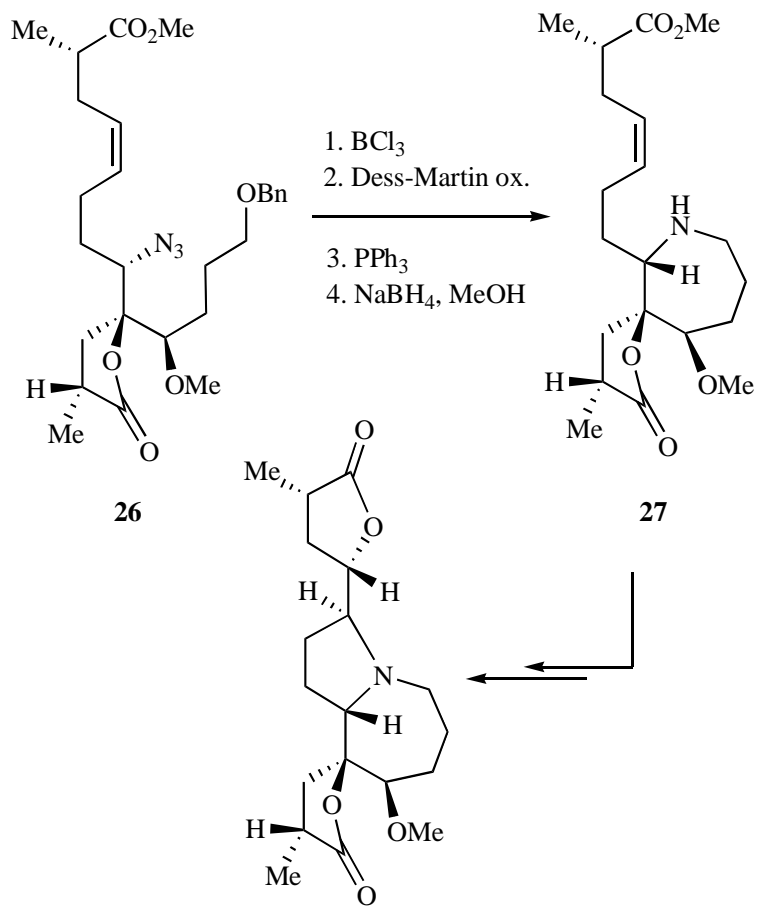

Scheme 8 required aldehyde was prepared from starting azide $\mathbf{2 6}$ by cleavage of benzyl ether and Dess-Martin oxidation of obtained primary alcohol (Scheme 8). Subsequent addition of triphenylphosphine and reduction of imine bond formed in the intramolecular aza-Wittig reaction gave a sevenmembered ring $\mathbf{2 7}$ precursor of the expected alkaloid $\mathbf{2 8}$.

The intramolecular aza-Wittig reaction is also a valuable tool for the construction of seven-membered-heterocyclic rings of polycyclic compounds like pyrazino[2,3-e]pyrrolo [1,2-a][1,4]diazepin-5-one derivatives 31 [9] (Scheme 9).

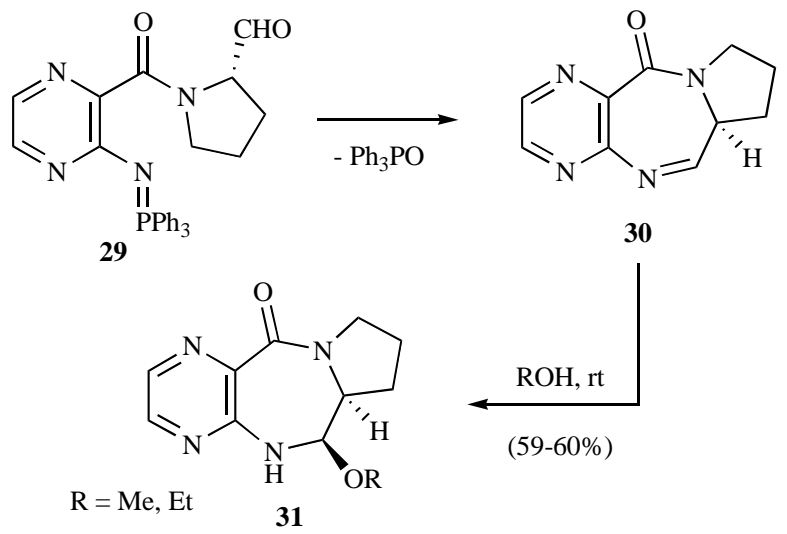

Scheme 9.

Similarly, this approach has been used for the synthesis of 5-azaazulene derivatives 35 [10]. (Scheme 10). An initial nucleophilic reaction between phosphazenes $\mathbf{3 2}$ and aldehydes 33 could afford intermediates 34, which after intramolecular aza-Wittig reaction gave the condensed bicyclic compounds 35 .

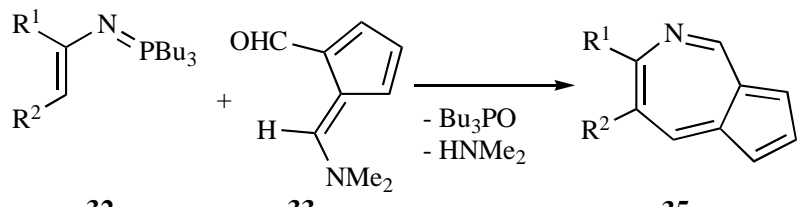

32 33 35<smiles>[R]/C(N=[Pb])=C(/[R])C(C1=CC=CC1CC)N(C)C</smiles>

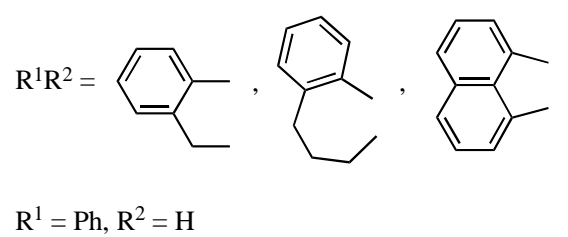

Scheme 10.

Likewise, the antibiotic DC-81 (38) can be synthesized by using the same strategy [11]. Treatment of azide $\mathbf{3 6}$ with triphenylphosphine at room temperature afforded the intramolecular aza-Wittig compound 37, which in turn could be converted into DC-81 (38) in a straightforward manner 
(Scheme 11). The same strategy has been used for the preparation of the antibiotic DC-81 (38) by intramolecular reductive cyclization with polymer-supported triphenylphosphine [12].<smiles>[2H]c1cc(N)c(C(=O)N2CCC[C@H]2C=O)cc1OC</smiles>

36

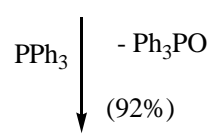<smiles>COc1cc2c(cc1OC)C(=O)N1CCC[C@H]1C=N2</smiles>

$37 \mathrm{R}=\mathrm{Bn}$

$38 \mathrm{R}=\mathrm{H}$

Scheme 11.

\subsection{Synthesis of Eight-Membered Ring Systems}

O'Neil et al. [13] reported the synthesis of eightmembered heterocycles such as benzodiazocine 40 through a Staudinger/intramolecular cyclization process (Scheme 12). This is, as far as we know, the first example of the use of Staudinger/aza-Wittig protocol for the construction of an eight-membered ring.<smiles>Nc1ccccc1C(=O)N1CCC[C@H]1CC=O</smiles><smiles>CC(C)OC1CCCCC1</smiles>

$(93 \%)$<smiles>O=C1c2ccccc2N=CC[C@@H]2CCCN12</smiles>

40
Scheme 12.

\section{PHOSPHAZENES DERIVED FROM KETONES}

Phosphazenes having a ketone substitution cyclize by intramolecular aza-Wittig reaction to give heterocyclic compounds. The first example was the formation of pyridine ring in the last step for the synthesis of the alkaloid nigrifactine [14], and has been widely applied in the preparation of 5-, 6and 7-membered heterocycles [3h].

\subsection{Synthesis of Five-Membered Ring Systems}

In the total synthesis of (-)-dendrobine (44), the fivemembered nitrogen heterocycle can be formed by intramolecular aza-Wittig reaction of azido ketone 41 [15]. Thus, treatment of $\mathbf{4 1}$ with triphenylphosphine gave polycyclic imine 43. Reduction of the imine moiety with sodium cyanoborohydride from the less hindered $\alpha$-face followed by reductive methylation of amine with paraformaldehyde and formic acid afforded enantiomerically pure (-)-dendrobine (44) (Scheme 13). In this synthesis, six stereogenic centres were induced, each in a stereoselective fashion, from a single chiral centre of the starting material.

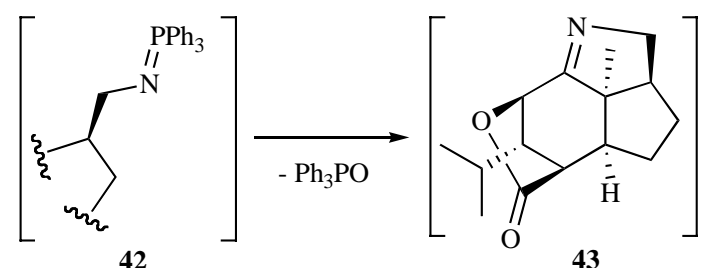

42

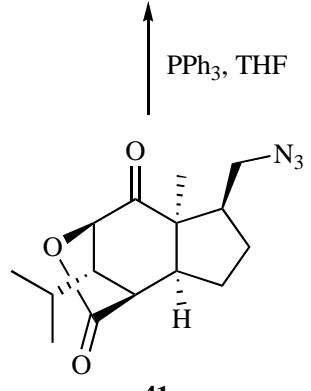

41
43

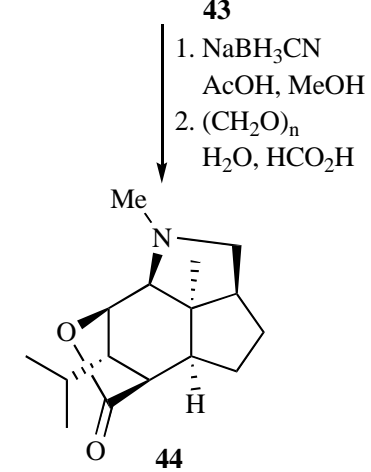

(42\% overall yield)
Scheme 13.

Nitta et al. [16] have reported enamine-type alkylation of vinylic phosphazenes onto $C-\alpha$ of conjugated ketones for the preparation of fused nitrogen heterocycles. Thus, $5 \mathrm{H}$ dicyclohepta $[b, d]$ pyrrole ring system $\mathbf{4 8}$ can be obtained through an enamine-type alkylation of the phosphazene $\mathbf{4 5}$ onto $C-\alpha$ of cyclic conjugated ketone $\mathbf{4 6}$ to give a ketofunctionalized phosphazene 47 (Scheme 14). This intermediate $\mathbf{4 7}$ then undergoes an intramolecular aza-Wittig reaction followed by hydrogen migration to give tricycle $\mathbf{4 8}$.
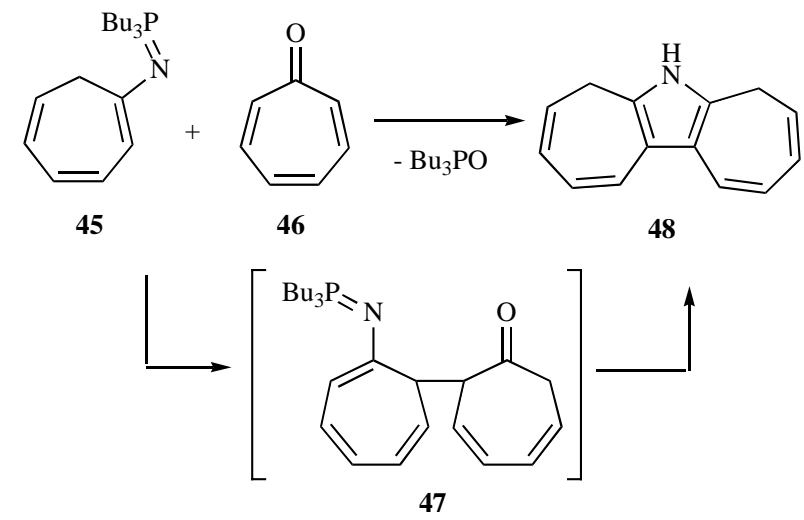

Scheme 14.

The same group has demonstrated the versatility of the enamine-type alkylation of vinylic phosphazenes/intramolecular aza-Wittig protocol, for the preparation of other fused nitrogen heterocycles [17]. Thus, the synthetic strategy for the preparation of $11 H$-cyclohepta $[b]$ indeno[2,1d] pyrrole $52\left(\mathrm{R}=\mathrm{R}^{1}=\mathrm{H}\right)$, and acenaphtho[1,2-b]cyclohepta $[d]$ pyrrole $52\left[\mathrm{RR}^{1}=(\mathrm{CH}=\mathrm{CH}-\mathrm{CH}=)\right]($ Scheme 15), involved the reaction of (tributyl)phosphazenes 49, respectively, with 2-chlorotropone $\mathbf{5 0}$, to afford bicyclic compounds. After subsequent intramolecular aza-Wittig reaction and subsequent aromatizing dehydrohalogenation gave the fused heterocycles 52. This methodology has been also used 
for the construction phenyl-substituted and annulated 5azaazulene (cyclopenta[c]azepine) derivatives [18].

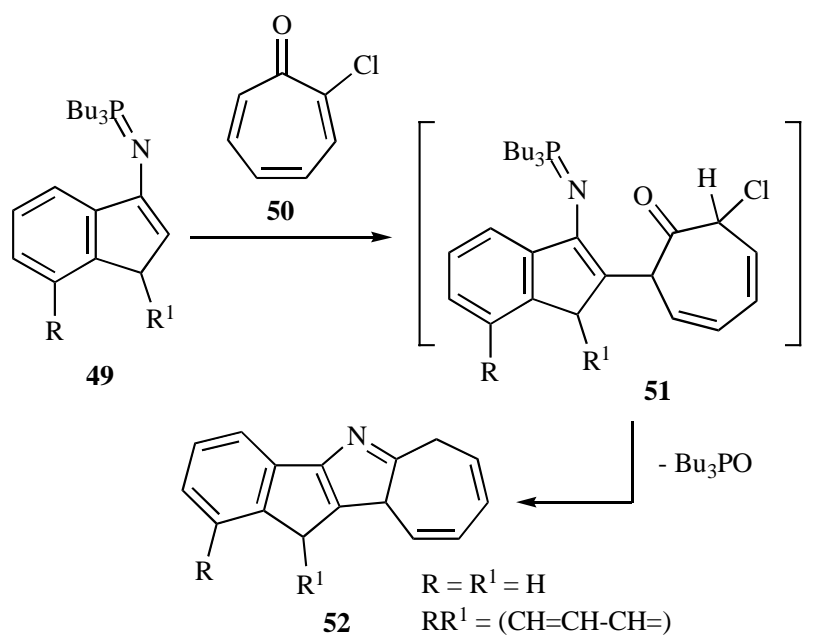

Scheme 15.

The formation of five-membered heterocycles through Staudinger/intramolecular aza-Wittig reaction can also be performed by solid-phase synthesis and has been applied to the first synthesis of lanopylin $B_{1}$ (56) [19]. The total synthesis, which takes only four steps, starts with a phase-transfer alkylation of diethyl 2-oxopropylphosphonate (53) with 2iodoalkyl azide affording azido phosphonate $\mathbf{5 4}$, which undergoes a phase-transfer Horner-Emmons-Wittig reaction with heptadecanal to provide azido enone 55. Intramolecular aza-Wittig reaction of enone $\mathbf{5 5}$ with polymer-supported triphenylphosphine in toluene completed the first total synthesis of lanopylin $\mathrm{B}_{1}(\mathbf{5 6})$ in $76 \%$ yield (Scheme 16).
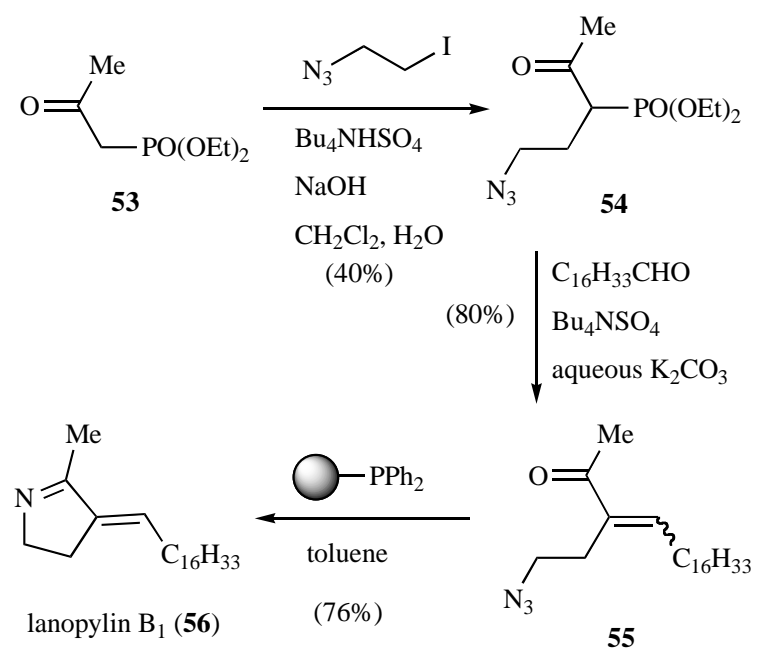

Scheme 16.

Substituted pyrrolines $\mathbf{5 9}$ can be synthesized in a simple one-pot procedure by microwave assisted intramolecular aza-Wittig reaction of phosphazene derived from $\gamma$-chlorobutyrophenone 57 [20]. Therefore, functionalized ketone 57 was treated with sodium azide and triethylphosphite in DMSO under microwave irradiation to give in high purities, yields and short reaction times substituted pyrrolines 59 (Scheme 17).<smiles>[X]c1ccc(C(=O)CCl)cc1[X]</smiles>

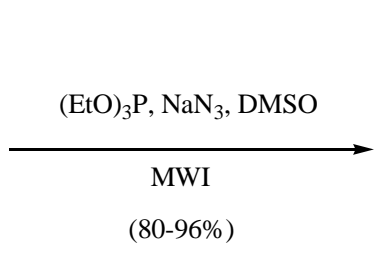

57<smiles>[Y]c1ccc(C2=NCCC2)cc1[X]</smiles><smiles>[Y]c1ccc(C(=O)ON=[Pt]CCCCCCC)cc1[Y]</smiles>

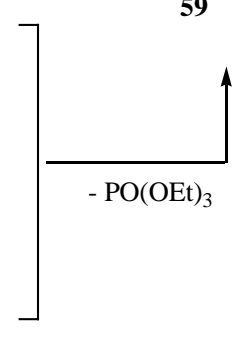

$\mathrm{X}=\mathrm{H}, \mathrm{OMe}, \mathrm{Br}, \mathrm{OH},{ }^{t} \mathrm{Bu}, \mathrm{Me}$

Scheme 17.

\subsection{Synthesis of Six-Membered Ring Systems}

Intramolecular aza-Wittig reactions of phosphazenes with ketone substitution also affords an excellent method for the preparation of six-membered heterocycles.

Unsaturated ketones $60\left(R^{2}=R^{3}=H\right)$ can be easily converted into seleno azides $\mathbf{6 1}$ regiospecifically. The intramolecular aza-Wittig reaction of these seleno azides $\mathbf{6 1}$ seemed to be an easy route to seleno derivatives of tetrahydropyridines 63 [21]. This approach has been extended to $\alpha$ allyl- $\beta$-ketoesters $60\left(\mathrm{R}^{3}=\mathrm{CO}_{2} \mathrm{Et}\right)$. Thus, seleno azides $\mathbf{6 1}$ obtained from these unsaturated compounds gave rise to ring-closure reactions through the ketonic function affording tetrahydropyridines 63 (Scheme 18).

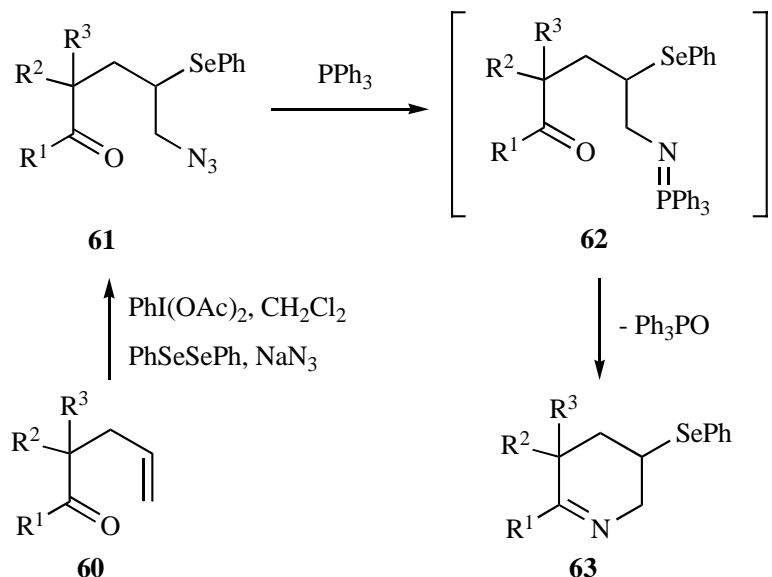

$$
\begin{aligned}
& \mathrm{R}^{1}=\mathrm{Me}, \mathrm{Ph}, 2 \text {-thienyl; } \mathrm{R}^{2}=\mathrm{R}^{3}=\mathrm{H} \\
& \mathrm{R}^{1} \mathrm{R}^{2}=-\left(\mathrm{CH}_{2}\right)_{3}-, \mathrm{R}^{3}=\mathrm{CO}_{2} \mathrm{Et}
\end{aligned}
$$

\section{Scheme 18.}

Optically active piperidine ring has been constructed by intramolecular aza-Wittig reaction of phosphazene 65 , obtained by Staudinger reaction of azide 64 with triphenylphosphine, in refluxing THF. The non-isolated imine $\mathbf{6 6}$ was reduced with sodium borohydride in ethanol to give anhydronupharamine (67) stereoselectively (Scheme 19) [22]. 


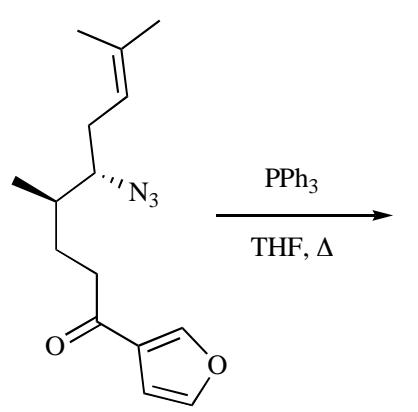

64
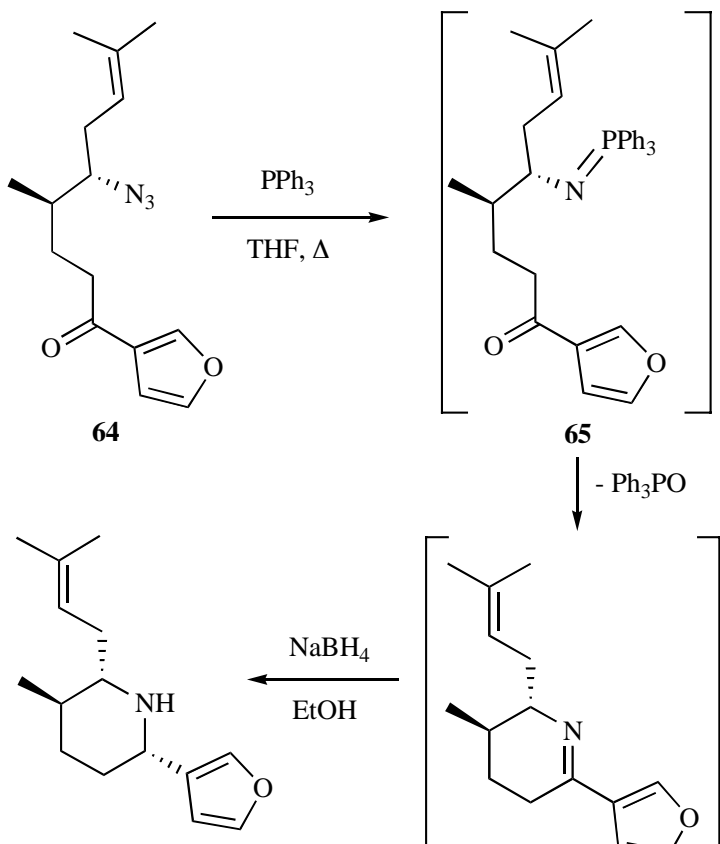

anhydronupharamine (67)

(77\% overall yield)
65

$\downarrow-\mathrm{Ph}_{3} \mathrm{PO}$

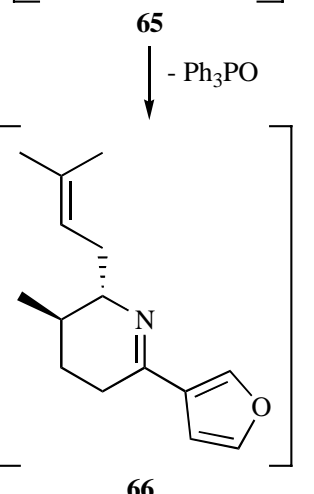

66

\section{Scheme 19.}

Eguchi et al. [23] reported the development of a new general route to pyridones as well as indolizines and quinolizines carrying a trifluoromethyl group on the bridgehead carbon of those skeletons. The strategy involves the intramolecular aza-Wittig reaction of easily available acylphosphazene 69 for the generation of 6-(trifluoromethyl)4,5-dihydro-2(3H)-pyridones 71 or $\mathbf{7 2}$ (Scheme 20). These lactams have been applied to the synthesis of some fusednitrogen heterocycles via radical cyclization of dihydropyridones.

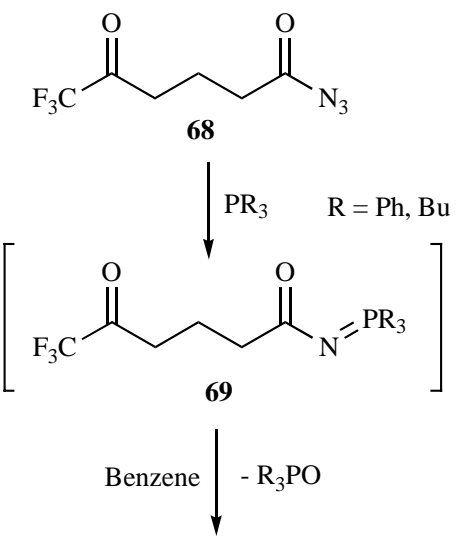

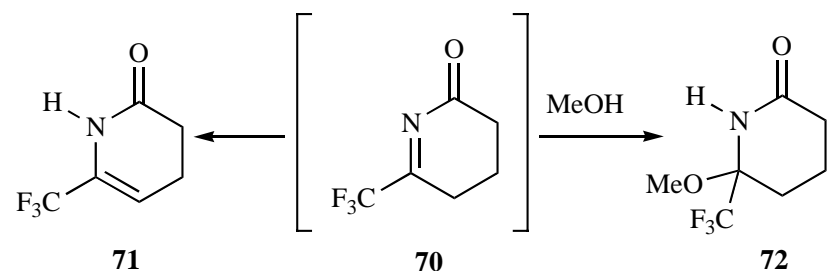

Scheme 20.

Microwave assisted intramolecular aza-Wittig reaction was used by De Kimpe et al. [24], for the synthesis of prin-

cipal bread flavour component, 6-acetyl-1,2,3,4-tetrahydropyridine. An approach towards acetal protected 6-acetyltetrahydropyridine $\mathbf{7 5}$ involved initial azidation of chloro- $\alpha$ ketoacetal $\mathbf{7 3}$ under classical conditions, followed by a smooth intramolecular aza-Wittig type reaction via the intermediacy of a phosphazene. The use of microwave irradiation [20] seems to favour the intramolecular aza-Wittig reaction and, shorter reaction times and better yields were necessary (Scheme 21).

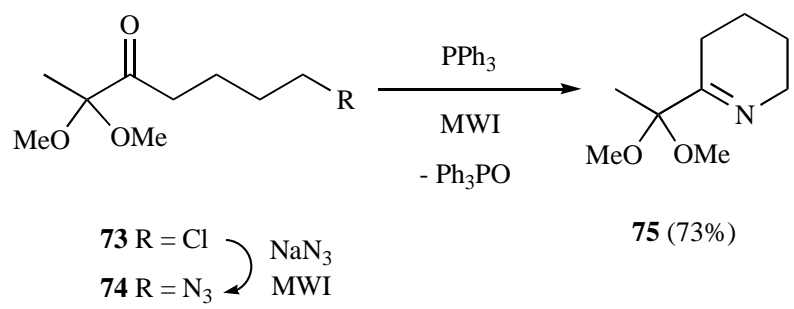

Scheme 21.

This methodology can also be used for the synthesis of polycycles containing a six-membered ring. Cryptand compound $\mathbf{7 7}$ has been prepared by intramolecular aza-Wittig reaction of ferrocenyl substituted azido ketone 76 [25]. [5]Ferrocenephane $\mathbf{7 6}$ underwent intramolecular aza-Wittig reaction by treatment with tributylphosphine at room temperature to give compound 77 bearing a 1,1'-disubstituted ferrocene bridge (Scheme 22).

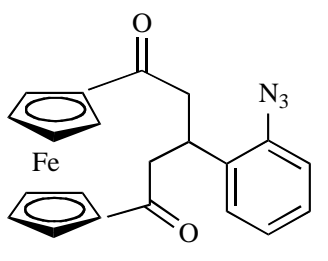

76

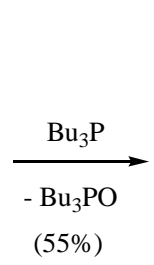

$(55 \%)$

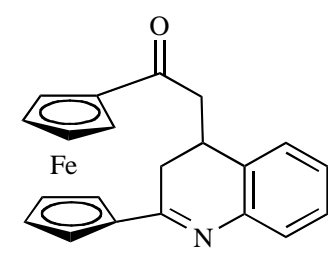

77
Scheme 22.

Likewise, six-membered nitrogen heterocycles have been formed by direct cyclization, via intramolecular aza-Wittig reaction of the non-isolable phosphazene $\mathbf{7 9}$ obtained by reaction of precursor azide 78, to afford isoxazolo[4,3c] quinolines 80 [26] (Scheme 23).<smiles>[R]C(=O)c1c(-c2ccccc2N)noc1[R]</smiles>

78

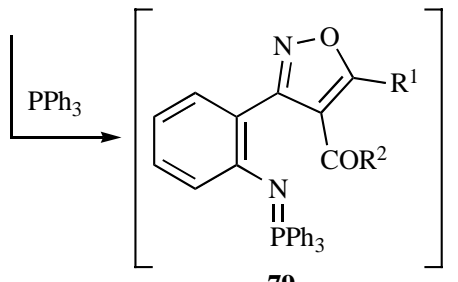

79<smiles>[R]c1nc2ccccc2c2noc([R])c12</smiles>

80

$$
\begin{aligned}
& \mathrm{R}^{1}=\mathrm{R}^{2}=\mathrm{Me}, \mathrm{Ph} ; \mathrm{R}^{1}=\mathrm{Me}, \mathrm{R}^{2}=\mathrm{Ph} \\
& \mathrm{R}^{1}=\mathrm{Ph}, \mathrm{R}^{2}=\mathrm{Et}
\end{aligned}
$$

Scheme 23 . 
This approach has been also used as the key step for the enantioselective synthesis of the marine indole alkaloid hamacanthin B (84) [27] (Scheme 24) and the antipode of hamacanthin A [28]. The central pyrazinone ring was achieved by reaction of azide $\mathbf{8 1}$ and tributylphosphine in toluene at room temperature followed by heating to provide the expected cyclized product $\mathbf{8 3}$ keeping the configuration of the $C-\alpha$ of starting azide. Detosylation of $\mathbf{8 3}$ with L-selectride provides hamacanthin B $(\mathbf{8 4})$.

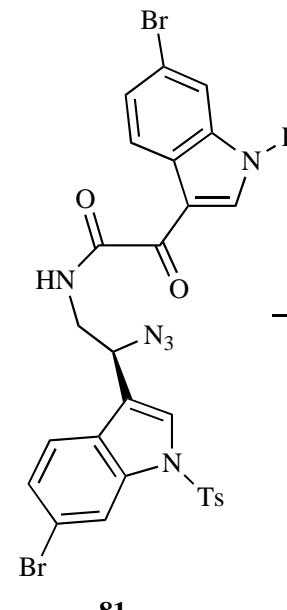

81<smiles>O=C1NC[C@H](c2c[nH]c3cc(Br)ccc23)N=C1c1c[nH]c2cc(Br)ccc12</smiles>

hamacanthin B (84)
$-\mathrm{Bu}_{3} \mathrm{PO} \downarrow(82 \%)$

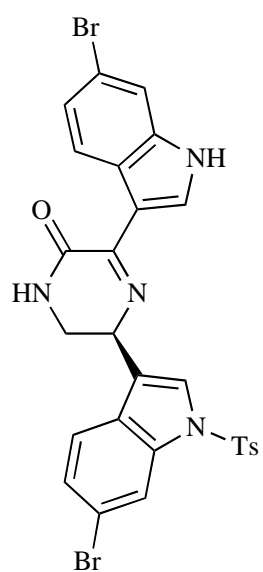

83

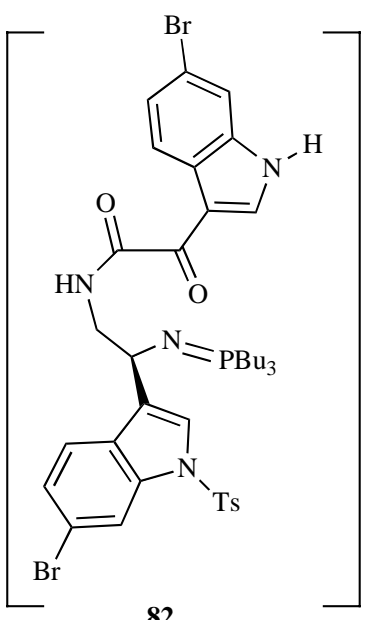

Scheme 24.

Reaction of $\mathrm{N}$-vinylic phosphazenes such as (inden-3ylimino)tributylphosphazene (85) with $\alpha, \beta$-unsaturated aldehydes and ketones 86, and $5 \mathrm{~mol} \% \mathrm{Pd}-\mathrm{C}$ gave $5 \mathrm{H}$ indeno[1,2-b]pyridines 89 (Scheme 25) [29]. Formation of compounds 89 could be explained by the initial enaminetype alkylation (Michael addition) of substrate $\mathbf{8 5}$ onto the $\beta$ carbon atom of enones 867. Intramolecular aza-Wittig reaction of keto functionalized phosphazenes 87 gave the dihydropyridines intermediates $\mathbf{8 8}$, which are dehydrogenated with $\mathrm{Pd}-\mathrm{C}$ to give compounds 89. The same authors described the preparation of 7,12-methanocyclodeca[b]pyridine ring systems [30] through reaction of annulene phosphazene with $\alpha, \beta$-unsaturated ketones, in a similar way to that described before.<smiles>CC(C)C=[Pt]=NC1=CCc2ccccc21</smiles>

85

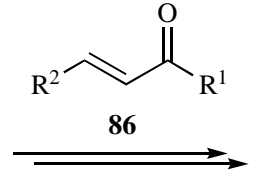

(1)

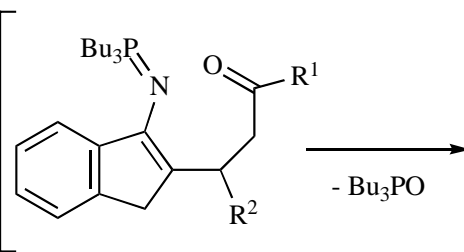

87
$\mathrm{R}^{1}=\mathrm{H}, \mathrm{Me}, \mathrm{Ph}$

$$
\mathrm{R}^{2}=\mathrm{H}, \mathrm{Me}, \mathrm{Ph}
$$<smiles>[R]c1cc([R2])c2c(n1)-c1ccccc1C2</smiles>

$89(33-89 \%)$<smiles>[R]C1=NC2=C(Cc3ccccc32)C([R])C1</smiles>

88

Scheme 25.

Intramolecular aza-Wittig reactions mainly involve phosphazenes generated by Staudinger reactions. In this context, a new efficient synthesis of thiadiazinones 92 has been recently reported by means of functionalized ketophosphazenes [31]. However, in this case phosphazenes were prepared by Kirsanov reaction (Scheme 26) [3h]. The synthesis implies treatment of 3-amino- $4 \mathrm{H}$-imidazol-4-ones $\mathbf{9 0}$ with triphenylphosphine, hexachloroethane, and triethylamine to afford directly $2 \mathrm{H}$-imidazo[2,1-b]-1,3,4-thiadiazin6(7H)-ones 92. The conversion involves initial transformation of 90 into phosphazenes $\mathbf{9 1}$ as reactive intermediates, which easily undergo intramolecular aza-Wittig reaction to give 92 (Scheme 26).

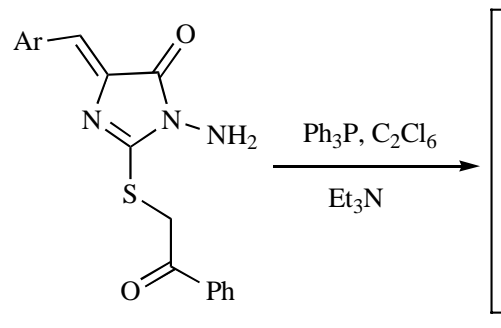

90<smiles>O=C1C(=C[13I])N=C2SCC(c3ccccc3)=NN12</smiles>

$(73-86 \%)$

$\mathrm{Ar}=\mathrm{Ph}, p-\mathrm{MeOC}_{6} \mathrm{H}_{4}$, 2-Furyl

Scheme 26.

\subsection{Synthesis of Seven-and Eight-Membered Ring Sys- tems}

The synthesis of the enamine-aminal heterocyclic core 95 found in the zoanthamine alkaloids has been reported through an enantiocontrolled construction of the sevenmembered heterocycle by an aza-Wittig reaction [32]. Direct intramolecular aza-Wittig condensation led to isolation of 
the tetrahydroazepine 94 in excellent yield (Scheme 27). Hemi-aminal 95 was produced by desilylation of $\mathbf{9 4}$, which resulted in ketalization, amination, and dehydration to the tetracyclic core $\mathbf{9 5}$ of the zoanthamine alkaloids.

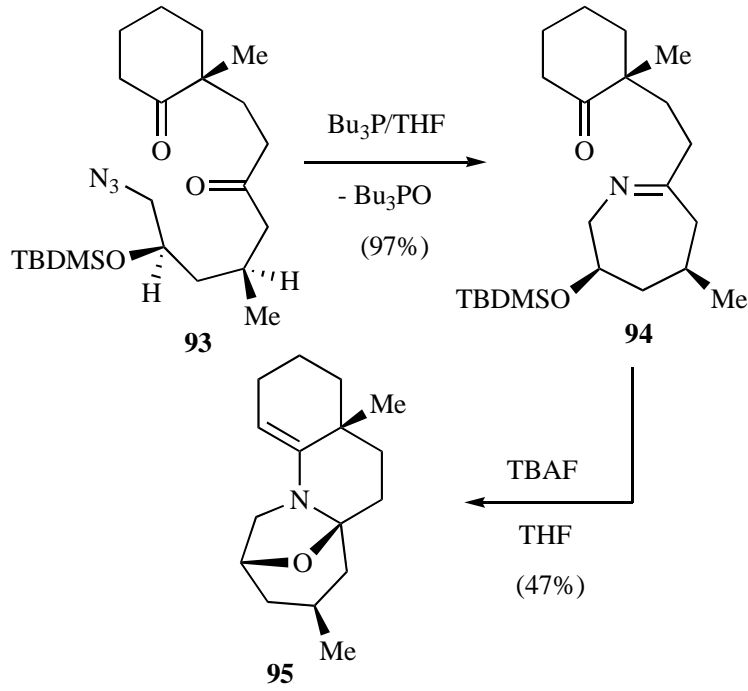

Scheme 27.

An efficient synthetic route to the spirally fused AG-ring model of pinnatoxin A has been devised using the intramolecular cyclization of an epoxy nitrile for the construction of the G-ring, followed by an aza-Wittig reaction to form the seven-membered cyclic imine [33] (Scheme 28). The cyclization of A-ring took place, when 99 was treated with triphenylphosphine and heated at $55^{\circ} \mathrm{C}$, to give $\mathbf{1 0 1}$ in $43 \%$ overall yield.

Intramolecular aza-Wittig reaction of phosphazenes $\mathbf{1 0 3}$ derived from amino azide derivatives with a keto function $\mathbf{1 0 2}$ led to 2,3,6,7-tetrahydro-1H-1,4-diazepines 104. Reduction of these compounds with lithium aluminium hydride afforded the corresponding saturated heterocycles 105 (Scheme 29) [34].<smiles>[R]C(=O)CC([R])N([R])CC([Y])N</smiles>

102<smiles>[R]C1CC([R])N([R])CC([R])N1</smiles>

105<smiles>[R]C(=O)CC([R])N([R])CC([R])N=[PbH]</smiles>

103<smiles>C1C[Pb]2C[Pb]1C2</smiles><smiles>[R]C1=NC([R])CN([R])C([R])C1</smiles>

104

$$
\begin{array}{ll}
\mathrm{R}=\mathrm{H}, \mathrm{Me}, \mathrm{Bn} ; & \mathrm{R}^{1}=\mathrm{H}, \mathrm{Me} \\
\mathrm{R}^{2}=\mathrm{H}, \mathrm{Me}, \mathrm{Ph} ; & \mathrm{R}^{3}=\mathrm{Me}, \mathrm{Ph}
\end{array}
$$

Scheme 29.

In the same way, the intramolecular aza-Wittig reaction is a valuable tool for the construction of seven-membered heterocyclic compounds like benzodiazepines and benzothiadiazepines 107 (Scheme 30) [35].

A straightforward intramolecular aza-Wittig reaction of azido- $\beta$-ketoesters for the preparation of heterocyclic secondary enamines has been recently developed by Wang et al. [36]. Thus, reaction of azido- $\beta$-ketoesters 108 with triphenylphosphine furnished the seven-membered $(n=1)$ or eightmembered $(n=2)$ heterocyclic enamines 111 through the Staudinger/intramolecular aza-Wittig tandem reaction and

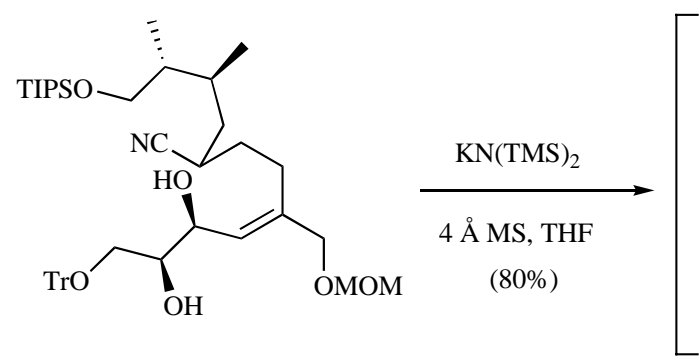

96

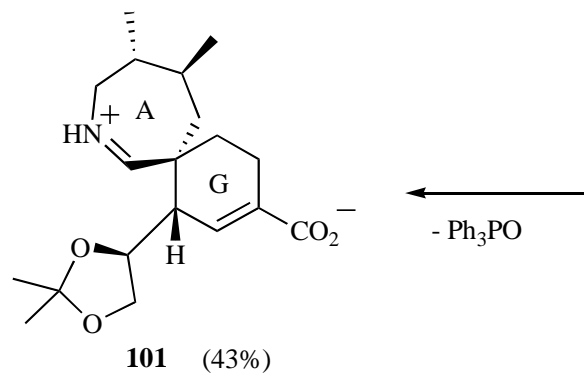<smiles>COCC(=CC1OC1CO)CCC(C#N)C[C@@H](C)[C@@H](C)CO[SnH3]</smiles>

97

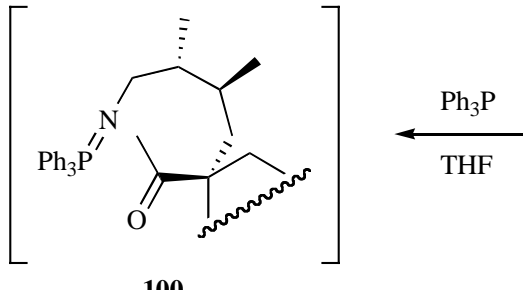

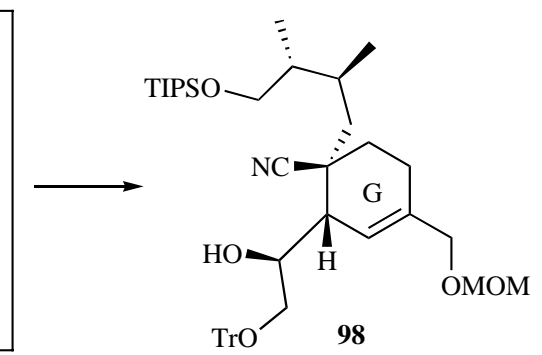

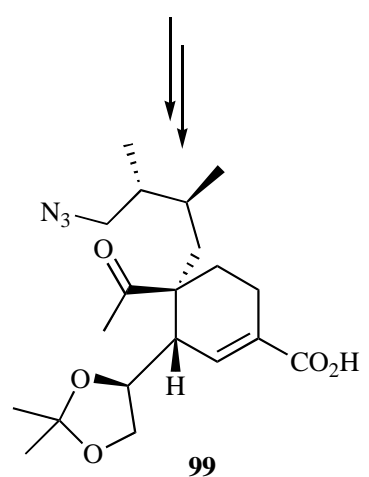

Scheme 28. 
<smiles></smiles>

Scheme 30.<smiles>[R]C(N)CC([R])CC([R])C(=O)CC(=O)OCC</smiles><smiles>[R]C(CC([R])N=[PbH])CC([R])C(=O)CC(=O)OCC</smiles>

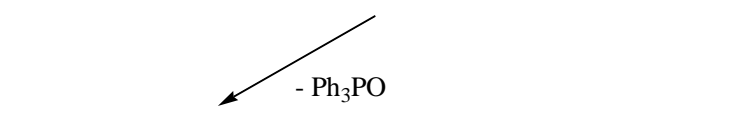

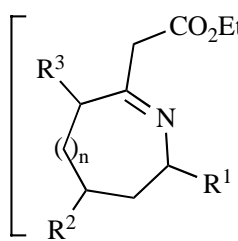

110

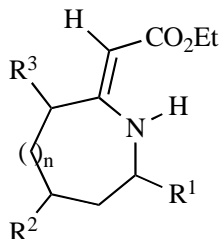

111

$$
\begin{aligned}
& \mathrm{R}^{1}=\mathrm{R}^{2}=\mathrm{R}^{3}=\mathrm{H}, n=1 \\
& \mathrm{R}^{1}=\mathrm{R}^{3}=\mathrm{H}, \mathrm{R}^{2}=\mathrm{Me}, n=1 \\
& \mathrm{R}^{1}=\mathrm{R}^{3}=\mathrm{Me}, \mathrm{R}^{2}=\mathrm{H}, n=1 \\
& \mathrm{R}^{1}=\mathrm{R}^{2}=\mathrm{R}^{3}=\mathrm{H}, n=2
\end{aligned}
$$

\section{Scheme 31 .}

subsequent imine-enamine tautomerization of cyclic imine 110 (Scheme 31).

\section{PHOSPHAZENES DERIVED FROM ESTERS}

It is well known that the carbonyl group of esters is less reactive than the carbonyl group of aldehydes and ketones in an aza-Wittig reaction. However, some examples have been reported for the preparation of 5- and 6-membered heterocycles through intramolecular aza-Wittig reaction of phosphazenes derived from esters [3h].

\subsection{Synthesis of Six-Membered Ring Systems}

The preparation of oxazolo[5,4- $b$ ]pyridines 118 [37] was accomplished by using vinylic phosphazenes 112. Thus, phosphazenes 112 and oxazolones 113 reacted smoothly in refluxing benzene or anisole leading to the formation of bi-

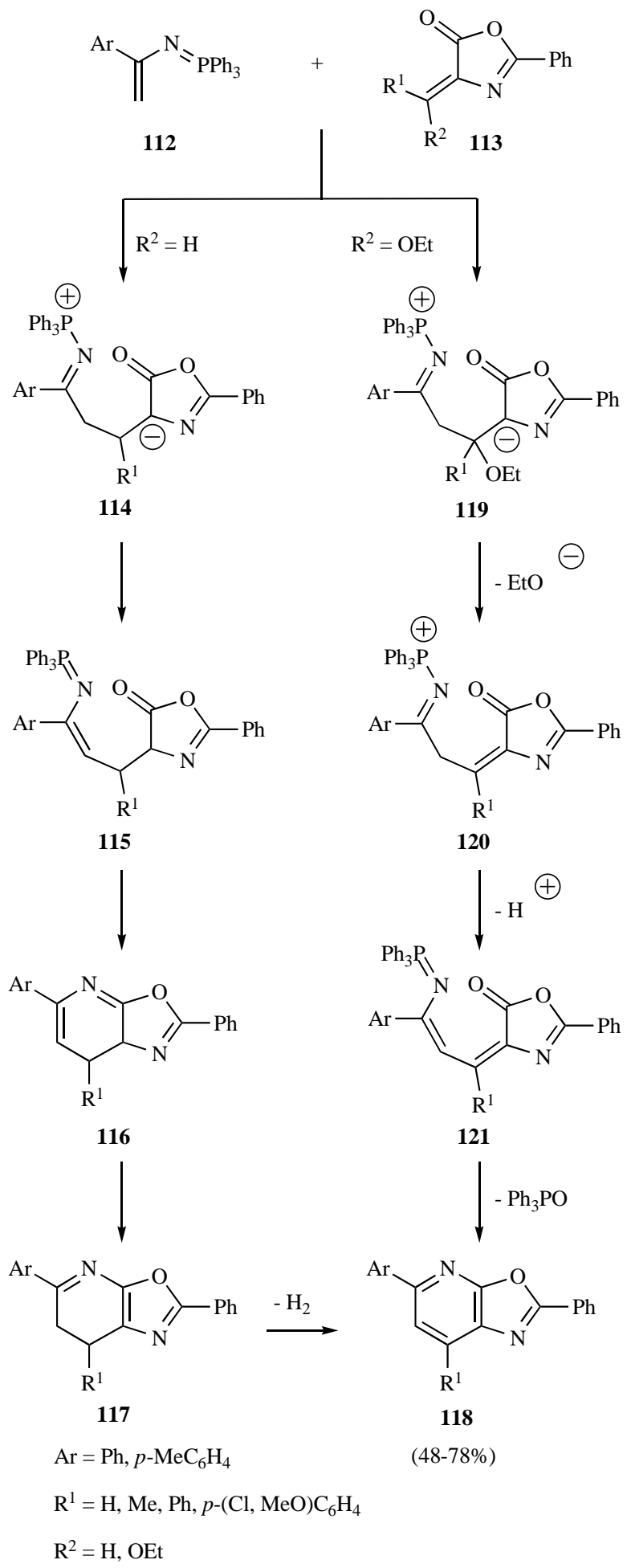

Scheme 32.

cycles 118 (Scheme 32). Phosphazenes 112 with ambident nucleophilicity react in this case as carbon nucleophiles rather than as nitrogen nucleophiles. Thus, the first step of the reaction can be envisaged as a conjugative addition (1,4addition) of the phosphazene $\mathbf{1 1 2}$ to the exocyclic double bond of oxazolone 113. The dipolar intermediate 114 thus produced is transformed into $\mathbf{1 1 5}$ by hydrogen shift and then into 116 by an aza-Wittig reaction. Tautomerization of $\mathbf{1 1 6}$ affords the dihydro-derivative 117. Dichlorodicyanoquinone 
(DDQ) was found satisfactory as an oxidizing agent and, products 118 were obtained in goods yields. However, treatment of the 4-ethoxymethyleneoxazol-5(4H)-ones 113 $\left(\mathrm{R}^{2}=\mathrm{OEt}\right)$ with phosphazenes $\mathbf{1 1 2}$ directly affords the corresponding oxazolopyridines $\mathbf{1 1 8}$. In this case after the nucleophilic addition of the phosphazene, ethoxide was eliminated from intermediate 119 producing $\mathbf{1 2 0}$ from which products 121 are formed on deprotonation of the $\mathrm{CH}_{2}$ group. The azaWittig reaction of compounds 121 affords 118 (Scheme 32).

The same strategy has been applied for the preparation of isoxazolo[4,3-c] quinolines 124 [26] through direct cyclization, via intramolecular aza-Wittig reaction of the nonisolable phosphazene containing an ester function 123, obtained by reaction of precursor azide $\mathbf{1 2 2}$ (Scheme $\mathbf{3 3}$ ).<smiles>[R]c1onc(-c2ccccc2N)c1C(=O)OCC</smiles>

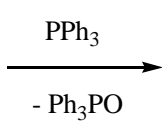

122<smiles>[R]c1onc(-c2ccccc2N=[PH2])c1C(=O)OCC</smiles>

Scheme 33.

\subsection{Synthesis of Seven-Membered Ring Systems}

Methods for the preparation of nitrogen seven-membered ring systems by the use of intramolecular aza-Wittig reaction have increased in the last decade.
In this way, benzodiazepines may be prepared from $\mathrm{N}$ - $(o$ azidobenzoyl)- $\alpha$-amino acid esters [38-40], and this methodology has been also applied for the first total synthesis of (-)-benzomalvin A (130) (Scheme 34) [41, 42]. Both the 6and 7-membered ring skeletons were efficiently constructed by the intramolecular aza-Wittig reactions as the key reactions.

Eguchi et al. [9, 43] have synthesized pyrazino[2,3e][1,4]diazepin-5-one derivatives $\mathbf{1 3 3}$ and/or 134 via the corresponding phosphazene 132 derived from 3-aminopyrazine-2-carboxylic acids and $\alpha$-amino acid derivatives, by the intramolecular aza-Wittig methodology (Scheme 35).

Analogously, the preparation of 1,3-benzoxazepines 137 has been developed via intramolecular aza-Wittig reaction of phosphazene 136 (Scheme 36) [44].

This methodology can be also applied to the preparation of pyrrolo[1,4]benzodiazepines in their imine form, and in general of $[1,4]$ benzodiazepines fused to a saturated heterocyclic ring (Scheme 37) [11, 45]. Likewise, functionalized phosphazenes 138 were converted, by heating, into the polycyclic iminoethers 139, in yields ranging from $82-95 \%$. This intramolecular aza-Wittig reaction involving an ester functionality as a key step for the preparation of pyrrolo[1,4]benzodiazepines 139 [11], was carried out in toluene in a sealed tube at $140^{\circ} \mathrm{C}$ or at reflux (Scheme 37).

Highly functionalized 1,4-benzodiazepin-5-one derivatives have been synthesized by solid-phase methods $[12,46]$. Bicyclic 142 and tricyclic heterocycles 144 were obtained by cyclization of azides 140 and 143, respectively, with polymer-supported triphenylphosphine, via the corresponding phosphazenes, at room temperature in toluene (Scheme 38). Subsequent heating at $100^{\circ} \mathrm{C}$ in the same solvent without further purification steps produced the intramolecular azaWittig products 142 and 144. The use of polymer-supported triphenylphosphine provides a more simplified purification procedure, relative to the corresponding solution-phase method [38].

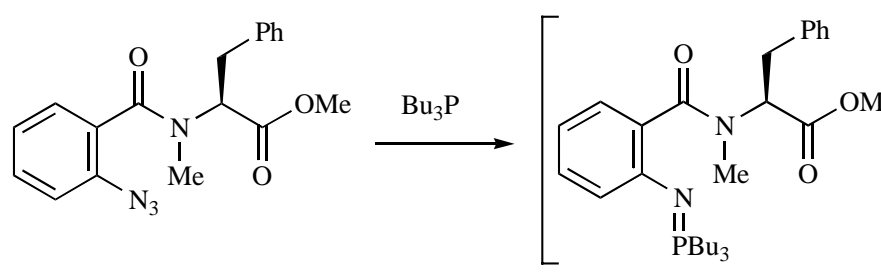

125<smiles>CN1C(=O)c2ccccc2-n2c(nc3ccccc3c2=O)[C@H]1Cc1ccccc1</smiles>

(-)-benzomalvin A (130
126

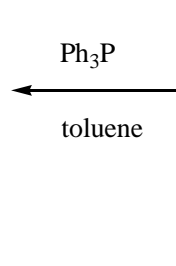<smiles>CN1C(=O)c2ccccc2N(C(=O)c2ccccc2N)C(=O)[C@@H]1Cc1ccccc1</smiles>

1. KHMDS, THF, $-78^{\circ} \mathrm{C}$<smiles>O=C(Cl)c1ccccc1</smiles>

$(82 \%)$<smiles>COC1=Nc2ccccc2C(=O)N(C)[C@@H]1Cc1ccccc1</smiles>

127

TFA: $\mathrm{H}_{2} \mathrm{O}: \mathrm{THF}(1: 1: 12.5)$, rt $(87 \%)$<smiles>CN1C(=O)c2ccccc2NC(=O)[C@H]1Cc1ccccc1</smiles>

128

Scheme 34. 
<smiles>[R1]OC(=O)C([R2])N([R])C(=O)c1nccnc1N</smiles>

131 $\mathrm{PPh}_{3}, \mathrm{C}_{2} \mathrm{Cl}_{6}, \mathrm{Et}_{3} \mathrm{~N}$<smiles>[R10]C(C(=O)O)N([R])C(=O)c1nccnc1N=P</smiles>

132 \begin{tabular}{r|r} 
xylene & $\begin{array}{c}-\mathrm{Ph}_{3} \mathrm{PO} \\
140^{\circ} \mathrm{C}\end{array}$
\end{tabular}<smiles>[R20]C1=Nc2nccnc2C(=O)N([R])C1[R]</smiles>

133<smiles>[R]C1C(=O)Nc2nccnc2C(=O)N1[R]</smiles>

134

$$
\begin{aligned}
& \mathrm{R}^{1}=\mathrm{H}, \mathrm{Me}, \mathrm{Bn}, \mathrm{Ph}_{2} \mathrm{CH}, p-\mathrm{MeOC}_{6} \mathrm{H}_{4} \mathrm{CH}_{2} \\
& \text { 2,4- } \mathrm{Me}_{2} \mathrm{C}_{6} \mathrm{H}_{3} \mathrm{CH}_{2} \\
& \mathrm{R}^{2}=\mathrm{H}, \mathrm{Me} \\
& \mathrm{R}^{1} \mathrm{R}^{2}=-\left(\mathrm{CH}_{2}\right)_{3} \text { - } \\
& \mathrm{R}^{3}=\mathrm{Me}, \mathrm{Et}
\end{aligned}
$$

\section{Scheme 35 .}<smiles>CCOC(=O)/C(N)=C/c1ccccc1OC(=O)F</smiles>

135

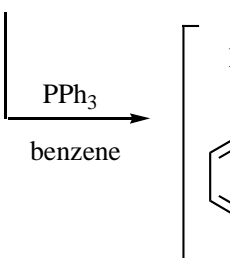

$\mathrm{R}=\mathrm{Me}, \mathrm{Ph}, \mathrm{OMe}$

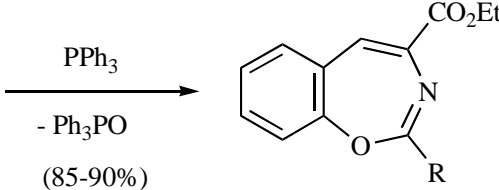

137<smiles>[R]C(=O)Oc1ccccc1/C=C(/N=[PH2])C(=O)OCC</smiles>

136

\section{Scheme 36.}

The synthesis of 1,4-benzodiazepine-2,5-diones 148 from polymer-supported $o$-azidobenzamides has been described by the split-and-mix method on solid-phase synthesis [47]. By using this approach and with the intramolecular azaWittig reaction of phosphazenes $\mathbf{1 4 6}$ as the key step, diverse of hybrid molecules combining a benzodiazepinedione nu-<smiles>[R16]OC1=Nc2ccccc2C(=O)N2C[C@@H]([R2])C[C@H]12</smiles>

138

139

$$
\begin{aligned}
& \mathrm{R}^{1}=\mathrm{Me}, \mathrm{R}^{2}=\mathrm{H}, \mathrm{R}=\mathrm{Bu}, \mathrm{Ph} \\
& \mathrm{R}^{1}=\mathrm{Et}, \mathrm{R}^{2}=\mathrm{OH}, \mathrm{R}=\mathrm{Bu}
\end{aligned}
$$

Scheme 37 .<smiles>[R][X]c1cccc(C(=O)N([R])C([R])C(=O)OC)c1N</smiles>

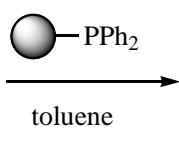

$(68-99 \%)$

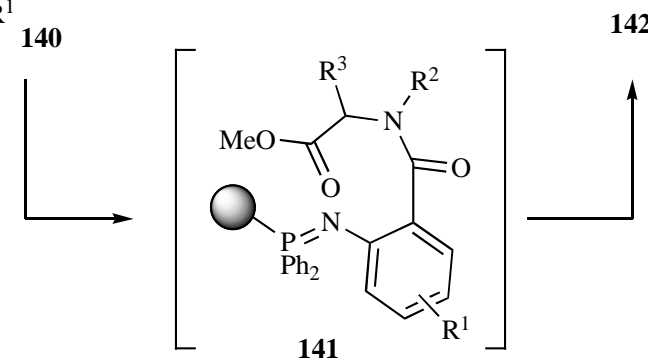

$$
\begin{aligned}
\mathrm{R}^{1}= & \mathrm{H}, 7-(\mathrm{Br}, \mathrm{I}, \mathrm{Cl}, \mathrm{Me}), 9-\mathrm{Me} \\
\mathrm{R}^{2}= & \mathrm{Me}, \mathrm{Bn}, p-(\mathrm{Ph}, \mathrm{MeO}) \mathrm{C}_{6} \mathrm{H}_{4} \mathrm{CH}_{2} \\
& \text { 3,4-(MeO) })_{2} \mathrm{C}_{6} \mathrm{H}_{3} \mathrm{CH}_{2} \\
\mathrm{R}^{3}= & \mathrm{H}, \mathrm{Me}, \mathrm{Bn}
\end{aligned}
$$

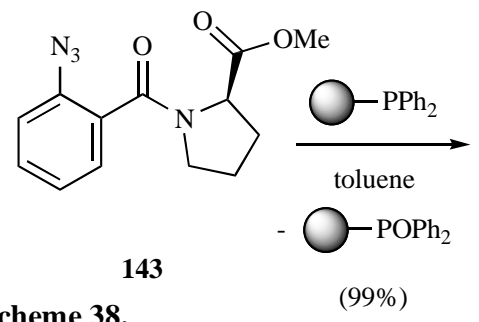<smiles>COC1=Nc2ccccc2C(=O)N2CCC[C@H]12</smiles>

144

Scheme 38.

cleus with an appended $N$-substituted glycine side chain have been synthesized (Scheme 39).

\subsection{Synthesis of Heterocycles Larger Than Seven- Membered Ring Systems}

More recently, the intramolecular Staudinger/aza-Wittig reaction of $\omega$-azido pentafluorophenyl (pfp) esters 149 has been successfully applied to the construction of seven to tenmembered lactams 150, demonstrating the generality and efficiency of the present tactic for the synthesis of mediumsized lactams (Scheme 40) [48]. Cyclization of $\omega$-azido pfp esters 149 proceeded smoothly at room temperature to give the corresponding 7- and 8-membered lactams 150, when $\mathrm{Bu}_{3} \mathrm{P}$ (5 equiv) as the reagent in high-dilution conditions was used. On the other hand, formation of much challenging larger 9- and 10-membered lactams called for elevated temperature conditions to attain satisfactory yields. 
<smiles>[X]c1ccc(N)c(C(=O)N(CC(=O)N(CC(=O)NO)CC(C)C)C([R])C(=O)OCC)c1</smiles>

145

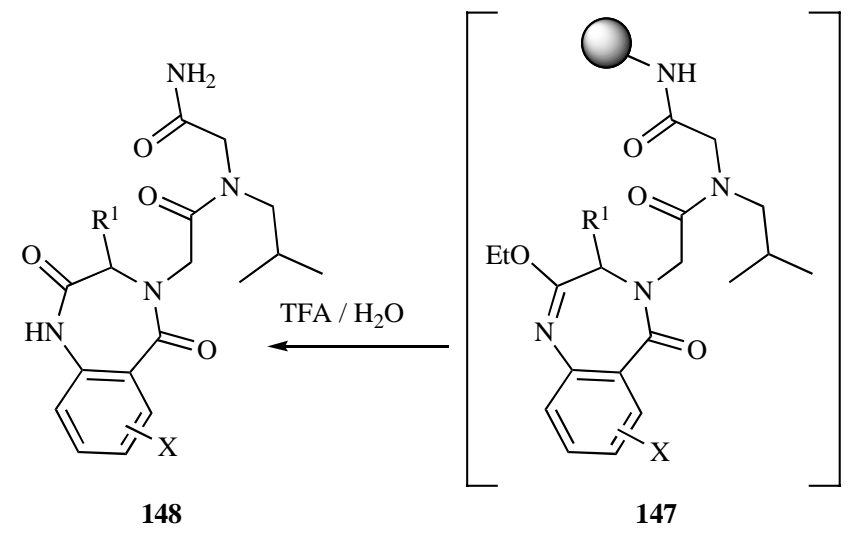

\section{Scheme 39.}

The formation of complex 13-membered macrocycles through Staudinger/intramolecular aza-Wittig reaction has

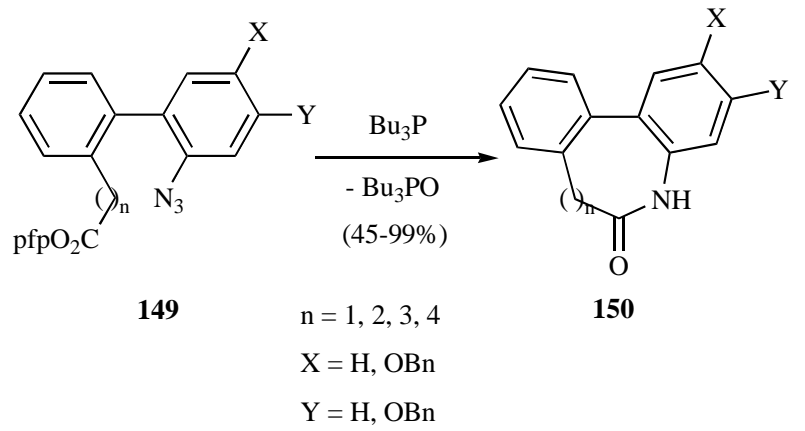

Scheme 39.

been applied to the total synthesis of (-)-ephedradine A (orantine) (154) $[49,50]$. The formation of the 13-membered iminoether $\mathbf{1 5 2}$ was successfully obtained by treatment of azide 151 with $\mathrm{Ph}_{3} \mathrm{P}$ in refluxing toluene under high-dilution conditions (Scheme 41). Hydrolysis of $\mathbf{1 5 2}$ by refluxing in $\mathrm{MeCN} / \mathrm{H}_{2} \mathrm{O}$ afforded the desired 13-membered macrolactam 153. Removal of the Ns group and simultaneous cleavage of $\mathrm{Cbz}$ group and benzyl ester with $\mathrm{BCl}_{3}$ yielded (-)ephedradine A (154).

\section{PHOSPHAZENES DERIVED FROM THIOESTERS}

\subsection{Synthesis of Five-Membered Ring Systems}

Recently, in developing a synthetic entry to the thiazoline-containing domain of the aprotoxin natural products, Forsyth et al. [51, 52] converted vicinal azido-thiolesters 155 into 2,4-disubstituted thiazolines 157 via sequential Staudinger reduction/intramolecular aza-Wittig reaction (Scheme 42). This method of the novo thiazoline formation provides a mild and versatile process that is particularly well suited to acid-sensitive substrates, and supports the application of the Staudinger/aza-Wittig process to thiazine formation in the context of a total synthesis of the apratoxin natural products.

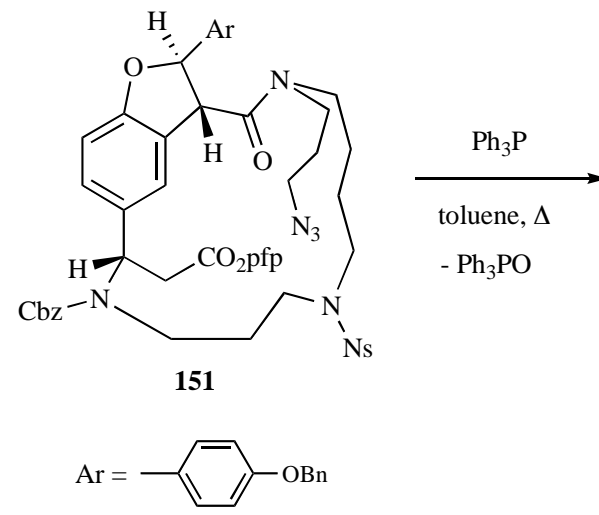

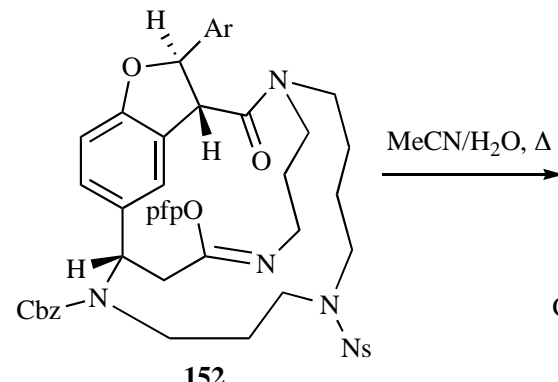

152

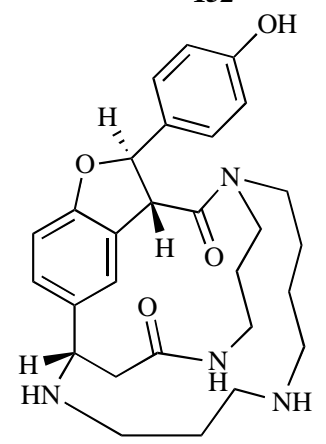

(-)-ephedradine A (154)

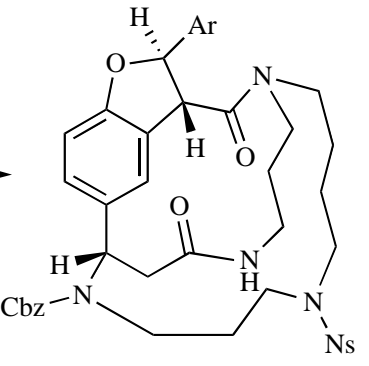

153

2. $\mathrm{BCl}_{3}, \mathrm{CH}_{2} \mathrm{Cl}_{2}(73 \%)$

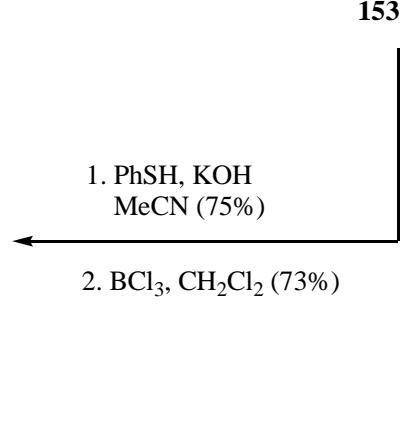

Scheme 41. 

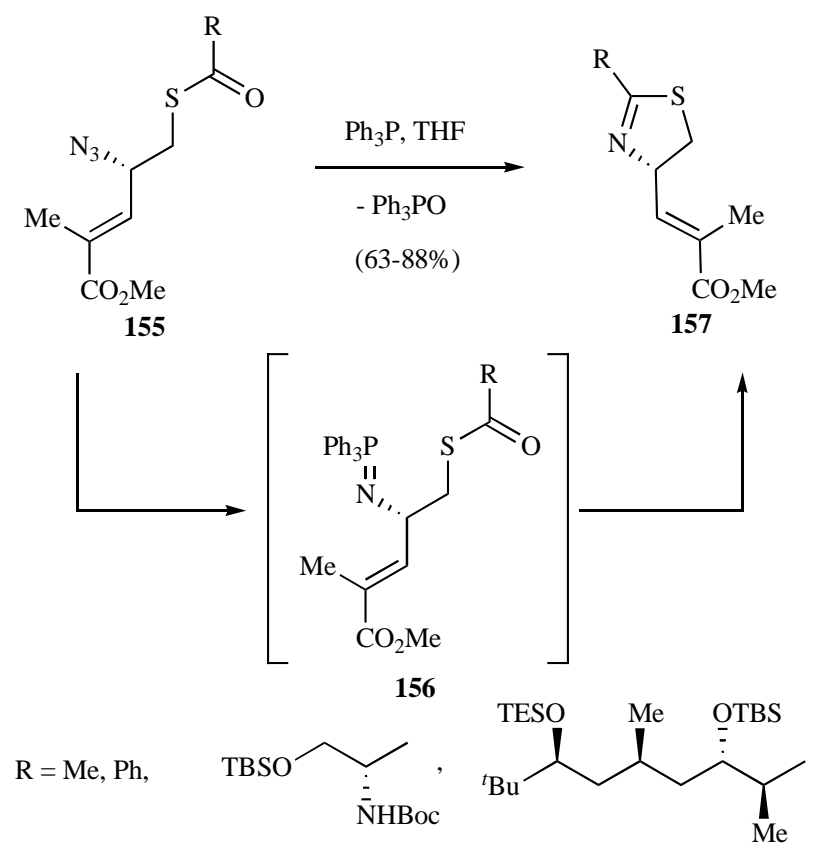

Scheme 42.

\subsection{Synthesis of Seven-Membered Ring Systems}

This methodology could be also applied to the preparation of pyrrolo[1,4]benzodiazepines in their imine form 159, and in general of $[1,4]$ benzodiazepines fused to a saturated heterocyclic ring (Scheme 43) [11,45].<smiles>O=C(NC1CCSC1=O)c1ccccc1N=Pc1ccccc1</smiles>

158<smiles>CCc1ccccc1NC(=O)C(CCS)CCS(=O)(=O)O</smiles>

Scheme 43.

\section{PHOSPHAZENES DERIVED FROM AMIDES}

\subsection{Synthesis of Five-Membered Ring Systems}

Some examples of intramolecular aza-Wittig imination reactions involving less reactive amide carbonyl groups have been reported, usually suffering from low yields. One of them is a convenient combination of intramolecular azaWittig strategy and a microwave technology for the preparation of the alkaloid cryptotackieine (163) [53, 54]. Thus, treatment of 3-(o-azidophenyl)quinolin-2-one (161) with trimethylphosphine in nitrobenzene at $150-180^{\circ} \mathrm{C}$ under microwave irradiation, after five-membered ring construction, afforded cryptotackieine (163) in $40 \%$ yield (Scheme 44 ).
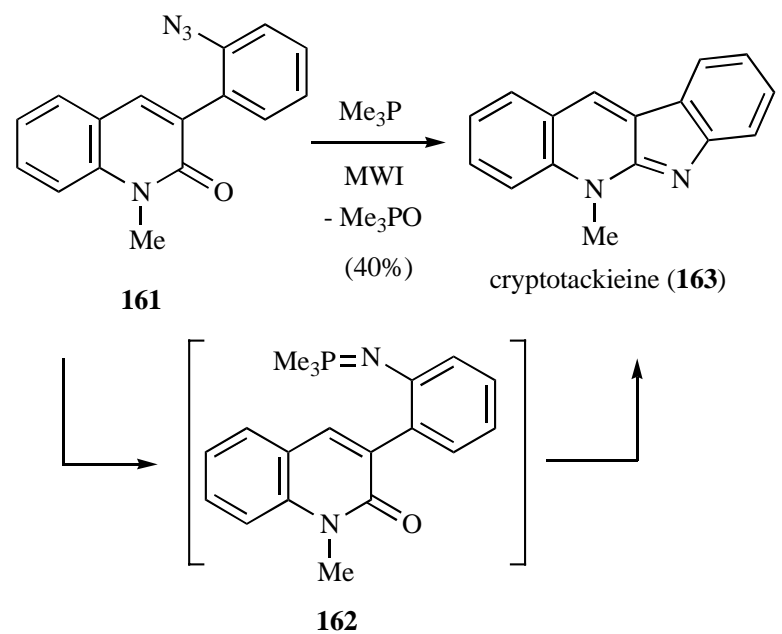

Scheme 44 .

\subsection{Synthesis of Six-Membered Ring Systems}

Six-membered heterocycles have also been prepared by using this approach. In this way, a general synthesis of functionalized quinazolino[3,4- $a$ ] perimidines which is capable of modification to allow the introduction of a wide range of substituents has been developed by Molina et al. [55]. These perimidines 166 were obtained when phosphazene 164 reacted with aroyl chlorides in the presence of triethylamine in a sealed tube at $160^{\circ} \mathrm{C}$ (Scheme 45). These rigorous conditions suggest that the conversion of $\mathbf{1 6 4}$ to 166 involves initial acylation of the perimidine ring instead of formation of an imidoyl chloride. Intramolecular aza-Wittig reaction between the carbonyl group of the amide moiety and the phosphazene group in $\mathbf{1 6 5}$ provides the cyclized product $\mathbf{1 6 6}$.<smiles>c1ccc(P=Nc2ccccc2C2=Nc3cccc4cccc(c34)N2)cc1</smiles>

\section{$\mathrm{ArCOCl}, \mathrm{Et}_{3} \mathrm{~N}$}

toluene, $160^{\circ} \mathrm{C}$

$-\mathrm{Ph}_{3} \mathrm{PO}$

$(40-57 \%)$

164

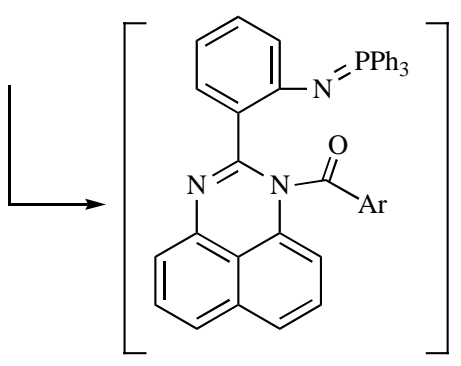

165

$$
\mathrm{Ar}=\mathrm{Ph}, p-\mathrm{MeC}_{6} \mathrm{H}_{4}, p-\mathrm{MeOC}_{6} \mathrm{H}_{4}
$$

\section{Scheme 45.}

In addition, employment of bisphosphazenes has undergone intramolecular aza-Wittig reaction to give phosphazene 168 derived from the 2-(o-azidophenyl)-4(3H)-quinazoli- 
none [56]. When bisphosphazene 167 was heated in dry toluene at reflux temperature, the phosphazene 168 was obtained in $65 \%$ yield (Scheme 46). This conversion involved an intramolecular aza-Wittig reaction where an amido group acted as the carbonyl partner.<smiles>O=C(NC(=O)c1ccccc1N=Pc1ccccc1)c1ccccc1</smiles>

167<smiles>O=c1[nH]c(-c2ccccc2N=Pc2ccccc2)nc2ccccc12</smiles>

Scheme 46.

This methodology has been used also for the synthesis of imidazo[4,5- $b$ ]quinolin-2-one ring [57]. When the $E / Z$ azide 169 was treated with tributylphosphine in $\mathrm{CH}_{2} \mathrm{Cl}_{2}$ at room temperature and the resulting phosphazenes $\mathbf{1 7 0}$ and 171 were heated at reflux temperature the 1,2-dihydroimidazo

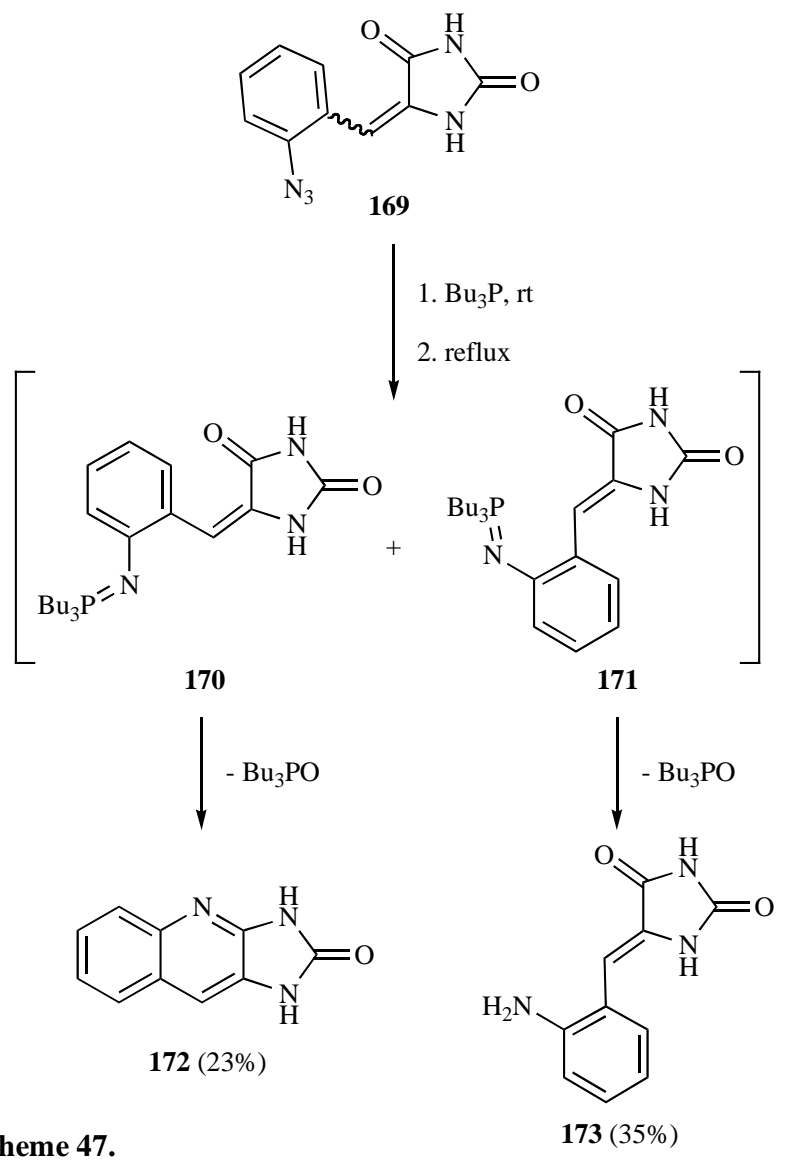

[4,5- $b$ ]quinolin-2-one 172 and the benzylidene hydantoin derivative 173 were isolated in a 23 and $35 \%$ yield, respectively (Scheme 47). Formation of compound 172 can be explained by intramolecular aza-Wittig reaction of the initially formed $E$-phosphazene, which could not be isolated, whereas the $Z$-phosphazene was hydrolyzed during the work-up to give 173.

$N$-(o-Azidobenzoyl)- $\alpha$-amino acid esters could afford also pyrrolo[2,1- $b$ ]quinozaline derivatives $\mathbf{1 7 6}$ or pyrrolo[2,1-c][1,4]benzodiazepine derivatives 177 . The formation ratio of heterocyclic compounds (6-membered ring versus 7-membered ring) was considerably dependant on carbonyl function ( $\mathrm{X}=\mathrm{OMe}, \mathrm{NEt}_{2}$ ) and phosphorus reagents. Exclusive formation of six-membered ring to give compound 176, through intramolecular aza-Wittig reaction with cyclic amide, has been observed for exocyclic amide derivatives (X $=\mathrm{NEt}_{2}$ ). However, a mixture of both compounds 176 and 177 was obtained for ester derivatives $(\mathrm{X}=\mathrm{OMe})$, obtaining compound $\mathbf{1 7 6}$ as a major product when triethyl phosphate ( $\mathrm{R}=\mathrm{OEt}$ ) was employed, which may be due to a less steric hindrance and mild reactivity (Scheme 48) [40, 58]. Thus, seven-membered ring compound $\mathbf{1 7 7}$ was predominantly formed with use of $\mathrm{Ph}_{3} \mathrm{P}$ or $\mathrm{Bu}_{3} \mathrm{P}$.
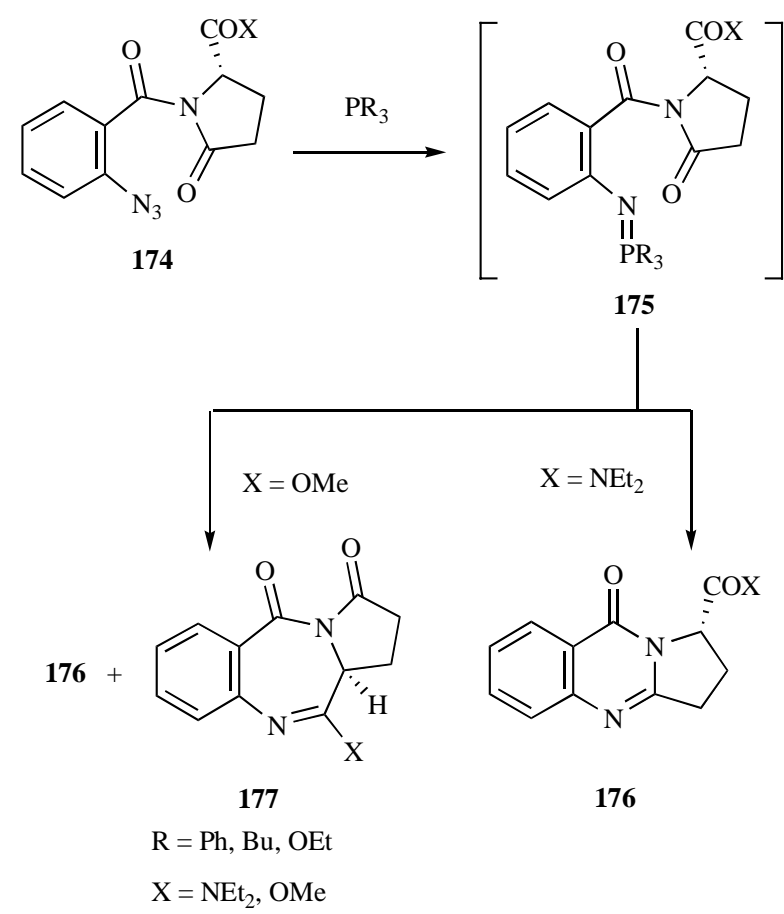

Scheme 48.

Molina et al. [59] also reported the intramolecular azaWittig reaction of a $\beta$-lactam carbonyl group. The intramolecular aza-Wittig reactions involving amide carbonyl group was applicable to the preparation of azeto[2,1$b$ ]quinazolines or quinazolin-8-ones 180 (Scheme 49). The method represents the first example of an aza-Wittig reaction of the $\beta$-lactam carbonyl group and requires the intermediacy of a highly reactive $N$-aryl-trimethylphosphazene 179, and it has only proven useful when it results in the formation of the six membered rings.

Simple quinazoline alkaloids and quinazoline alkaloids containing indole skeleton such as rutercarpine, tryptanthrin [60] and antitumor agent Batracylin (NCS-320846) [61] 
<smiles>[R][C@H]1N([X]c2ccccc2N)C(=O)C1([R])[R2]</smiles>

1. $\mathrm{Me}_{3} \mathrm{P}$, toluene, $\mathrm{rt}$

2. toluene, $\Delta$

$-\mathrm{Me}_{3} \mathrm{PO}$

$(40-90 \%)$

178<smiles>[Y]c1ccccc1N=[Y16]CCC</smiles>

$\mathrm{X}=\mathrm{CH}_{2}, \mathrm{CO}$

179

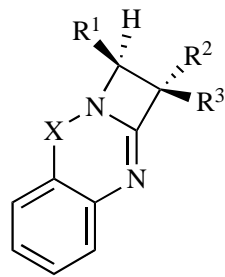

180

$\mathrm{R}^{1}=\mathrm{H}, p-\left(\mathrm{Cl}, \mathrm{Me}, \mathrm{NO}_{2}, \mathrm{MeO}\right) \mathrm{C}_{6} \mathrm{H}_{4}$,

$\mathrm{Ph}, \mathrm{MeCO}_{2}, \mathrm{PhCO}_{2}$

$\mathrm{R}^{2}=\mathrm{H}, \mathrm{Me}, \mathrm{Ph}$

$\mathrm{R}^{3}=\mathrm{H}, \mathrm{Ph}$

\section{Scheme 49.}

have been constructed via intramolecular aza-Wittig reaction of amide derivatives (Scheme 50). The fused quinazoline ring could be synthesized efficiently via the consecutive Staudinger/intramolecular aza-Wittig reaction of corresponding azides 181 with phosphine to afford heterocyclic compounds 183 under very mild reaction conditions.

Likewise, heterocycles such as circundatin F, sclerotigenin and ent-fumiquinazoline $\mathrm{G}$ (187) have been prepared by the intramolecular aza-Wittig procedure [62]. The sequence provides a short and efficient route to the fused quinazolinone ring system 186 (Scheme 51).<smiles>[R]C(=O)N([R])[X]c1cc([Y])ccc1N</smiles>

181<smiles>[R10]CCCCCC[R16]</smiles>

183

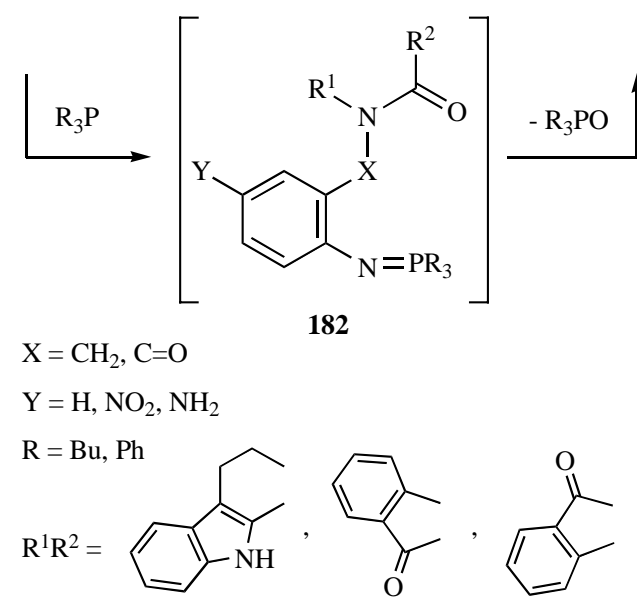

Scheme 50.

For the last step in the synthesis of benzomalvin A (189), azide derivative $\mathbf{1 8 8}$ was treated with triphenylphosphine to generate the corresponding phosphazene which reacted with the amide function to afford (-)-benzomalvin A (189) (Scheme 52) [42]. Comparison of the spectral and physical data of the synthetic product and those reported for the natural product (-)-benzomalvin A (189) gave satisfactory matching results.

Intramolecular aza-Wittig reaction of amide carbonyl group has also been used for the preparation of six-

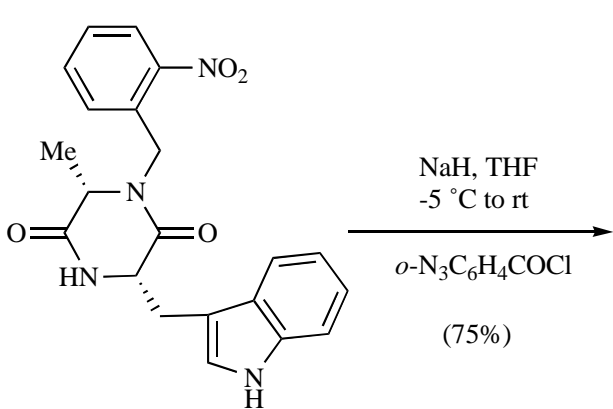

184

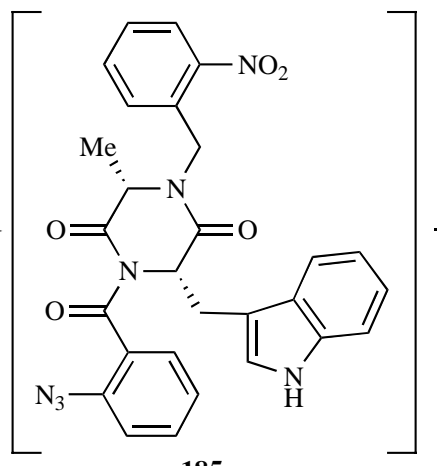

185

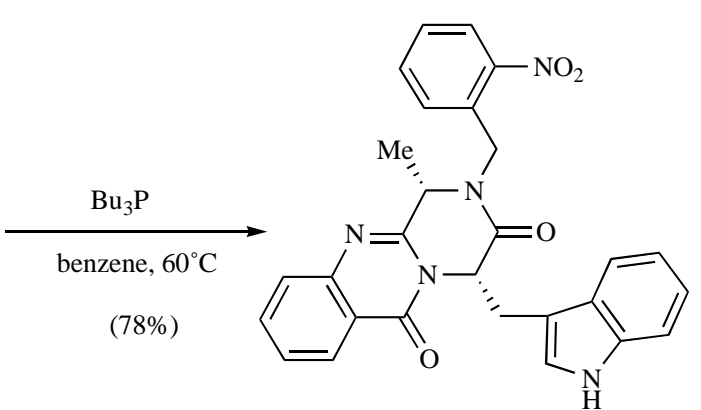

186<smiles>C[C@H]1NC(=O)[C@H](Cc2c[nH]c3ccccc23)n2c1nc1ccccc1c2=O</smiles><smiles>CCC(C)O</smiles> 
<smiles>CN1C(=O)c2ccccc2N(C(=O)c2ccccc2N)C(=O)[C@H]1Cc1ccccc1</smiles>

188

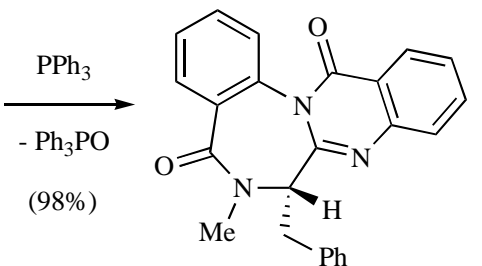

(-)-benzomalvin A (189)
Scheme 52.<smiles>[X]c1cc(N)c(C(=O)N2C(=O)c3ccccc3C(=O)N(C(=O)c3cc([Y])c([X])cc3N)c3ccccc32)cc1[Y]</smiles>

190

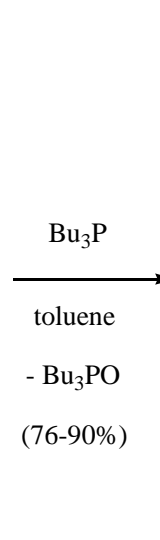

$\mathrm{X}=\mathrm{Y}=\mathrm{H}, \mathrm{OMe}$

$\mathrm{X}=\mathrm{Cl}, \mathrm{Y}=\mathrm{H}$<smiles></smiles>

191
Scheme 53.

membered ring of benzopolyazamacrocycles by Eguchi et al. [63]. The quinazolinone annelation of lactams $\mathbf{1 9 0}$ provides compounds 191. Further reductive ring enlargement sequence provides a novel route to benzofused polyazamacrocycles (Scheme 53).

Similarly, formation of six-membered heterocycles through intramolecular aza-Wittig reaction has been used for the preparation optically active $(S)-(-)$-vasicinone (194) (Scheme 54) [64]. After $O$-TBDMS protection, $o$-azidobenzoylation followed by treatment of compound 192 with tributylphosphine and a subsequent desilylation afforded $(S)$ (-)-vasicinone (194) via the tandem Staudinger/intramolecular aza-Wittig reaction (Scheme 54). Recently, deoxyvasicinone and related heterocycles have been synthesized through the solid-phase intramolecular aza-Wittig reaction employing a polymer-supported triphenylphosphine [46].

Synthetic approaches to 1-arylmethylenepyrazino[2,1$b$ ]quinazoline-3,6-diones 196 have been studied and the best results were obtained when azido heterocycles 195 were subjected to intramolecular aza-Wittig reaction (Scheme 55) [65]. The cyclization to heterocycles 196 took place through the amide group and the phosphazene moiety in the starting precursors. The same group has applied this approach to the synthesis of hexacyclic 7,10,16,16a-tetrahydro- $11 \mathrm{H}$ quinazolino[2',3':3,4]pyrazino[1,2- $b] \beta$-carboline-5,8-diones, dihydro- $C$-homo analogs [56], and other analogues of $N$ acetylardeemin $[67,68]$, inhibitor of multi-drug resistance (MDR) to antitumor agents.
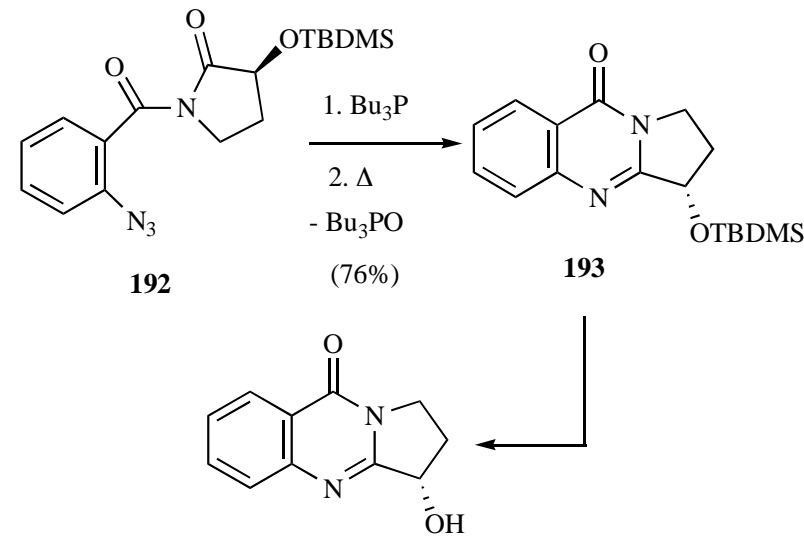

(S)-(-)-vasicinone (194)

Scheme 54.<smiles>[R]C1C(=O)N/C(=C\c2ccc(OC)cc2)C(=O)N1C(=O)c1ccccc1N</smiles><smiles>[R][C@H]1[C@@H]([R])C(=O)N/C(=C\c2ccc(OC)cc2)c2nc3ccccc3c(=O)n21</smiles>

Scheme 55.

A concise building block approach to a diverse multiarrayed library of the circumdatin family of natural products has been recently reported [69]. This synthetic strategy relied on an efficient formation of the fused quinazolinone ring system using polymer-supported phosphine in an intramolecular aza-Wittig reaction as a key step. In this manner, a diverse library of benzodiazepine-quinazolinone alkaloids (circumdatins) 198 has been prepared by treatment of azides 197 with polymer-supported triphenylphosphine (Scheme 56). Following the same strategy, the libraries incorporating pentacyclic derivatives, such as derivatives 199 and 200 were also prepared.

\subsection{Synthesis of Seven-Membered Ring Systems}

By means of intramolecular aza-Wittig reaction between phosphazene and amide moiety of compounds 202 sevenmembered ring can also be constructed. However, in this case higher temperatures are required for the synthesis of 1,3-benzodiazepines $\mathbf{2 0 3}$ comparing with temperatures required for analogous phosphazenes but with ester substitution (Scheme 57) [44]. 
<smiles>[R][Y]1cccc2c1C(=O)N([R])CC(=O)N2C(=O)c1ccccc1N</smiles>

Scheme 56.<smiles>[R]C(=O)Nc1ccccc1/C=C(/[N])C(=O)OCC</smiles>

201<smiles>[R]C(=O)Nc1ccccc1/C=C(/N=[PH2])C(=O)OCC</smiles>

202

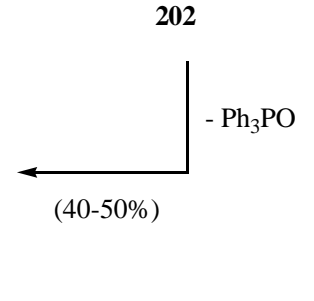

$\mathrm{R}=\mathrm{Me}, \mathrm{Ph}, \mathrm{OMe}$

\section{Scheme 57.}

\section{PHOSPHAZENES DERIVED FROM ANHYDRIDES}

The carboxylic acid anhydrides derivatives are able to undergo lactamization by intramolecular aza-Wittig reaction with the phosphazene moiety; however, only one example has been reported showing this behaviour. Azido acid derivatives, after activation of the carboxyl groups as mixed anhydrides 204, can be converted to macrolactams 207 in good yields by treatment with tributylphosphine (Scheme 58) [70]. This procedure has been fruitfully applied to other difficult to cyclise substrates, such as secondary azides $(\mathrm{R}=$ $\mathrm{Me}$ ) and a reluctant 10-membered ring, sterically hindered

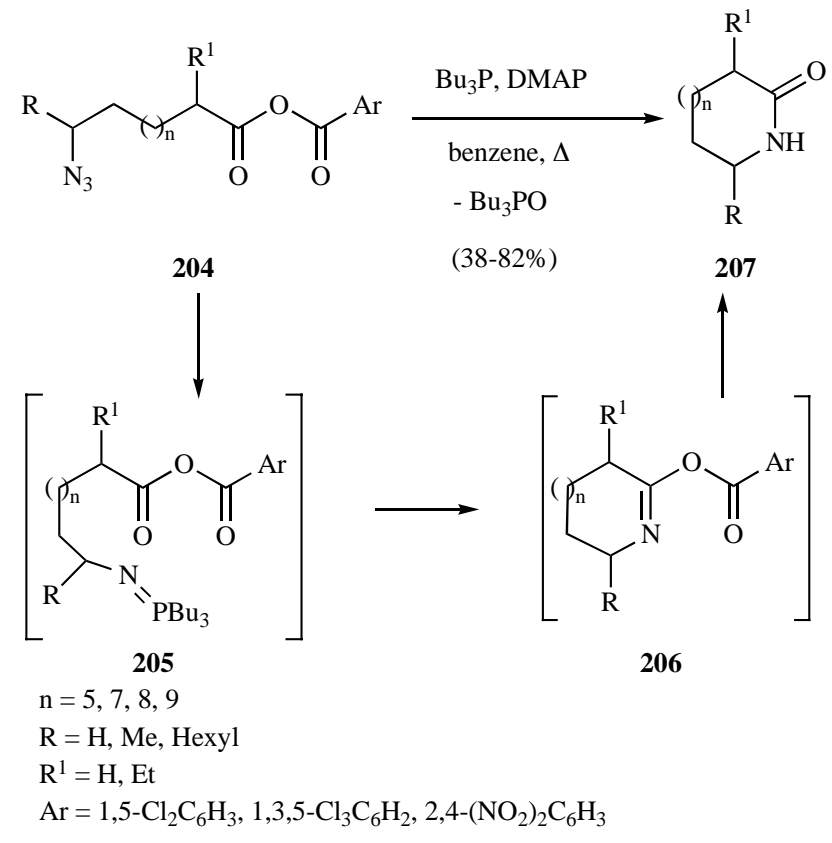

Scheme 58.

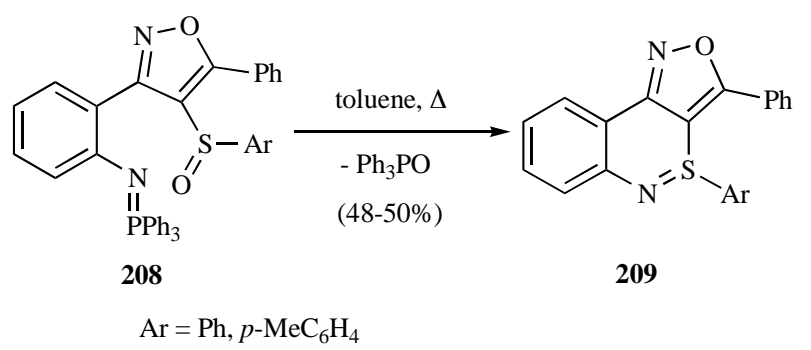

Scheme 59.

azides $(\mathrm{R}=$ hexyl) and a 13-membered lactam, and a more reactive primary azide $(\mathrm{R}=\mathrm{H})$ and a more accessible 14membered ring.

\section{PHOSPHAZENES DERIVED FROM SULFIMIDES}

Finally, the use of phosphazenes in other intramolecular aza-Wittig type reactions for the formation of hetero bonds other than $\mathrm{C}=\mathrm{N}$ is rare. In particular, there is only one example, recently reported, that details the synthesis of the $\mathrm{N}=\mathrm{S}$ (sulfimide) bond involving the use of $\mathrm{S}=\mathrm{O}$ functionality. Thus, the synthesis of a cyclic sulfimide 209 involving an intramolecular aza-Wittig type ring-closure process between a sulfoxide and a phosphazene moiety of compound 208 is reported [71]. Treatment of compounds 208 in anhydrous toluene at reflux gave triphenylphosphine oxide together with the isoxazolo[4,3-c][2,1]benzothiazines 209 (Scheme 59).

\section{CONCLUSION}

In summary, this review has presented recent progress in the synthesis of heterocyclic compounds based on the intramolecular aza-Wittig reaction of phosphazenes with several carbonyl or analogous substituents. These results indi- 
cate the importance and utility of these phosphazenes as versatile building blocks in heterocycle construction, ranging from simple monocyclic compounds to complex polycyclic and macrocyclic systems. In many cases, synthesis is carried out stereoselectively and the resulting compounds are physiologically active or are potential intermediates in the synthesis of physiologically active compounds including analogues of natural products.

\section{REFERENCES}

[1] Staudinger, H.; Meyer, J. Helv. Chim. Acta, 1919, 2, 635-646.

[2] Eguchi, S.; Okano, T.; Okawa, T. Rec. Res. Dev. Org. Chem. 1997, 1,337-346.

[3] (a) Fresneda, P. M.; Molina, P. Synlett, 2004, 1-17. b) Arques, A.; Molina, P. Curr. Org. Chem. 2004, 8, 827-843. c) Hartung, R.; Paquette, L. Chemtracts 2004, 17, 72-82. d) Wamhoff, H.; Richardt, G.; Stølben, S. Adv. Heterocycl. Chem. 1995, 64, 159249. e) Molina, P.; Vilaplana, M. J. Synthesis 1994, 1197-1218. f) Nitta, M., In Reviews on Heteroatom Chemistry, Vol. 9; Oae, S., De.; MYU: Tokyo, 1993, p. 87. g) Gololobov, Y. G.; Kasukhin, L. F. Tetrahedron 1992, 48, 1353-1406. h) Barluenga, J.; Palacios F. Org. Prep. Proced. Int. 1991, 23, 1-65.

[4] Maughan, M. A. T.; Davies, I. G.; Claridge, T. D. W.; Courtney, S.; Hay, P.; Davis, B. G. Angew. Chem. Int. Ed. 2003, 42, 37883792 .

[5] Timmer, M. S. M.; Risseeuw, M. D. P.; Verdoes, M.; Filippov, D. V.; Plaisier, J. R.; van der Marel, G. A.; Overkleeft, H. S.; van Boom, J. H. Tetrahedron: Asymmetry 2005, 16, 177-185.

[6] Pawlas, J.; Vedsø, P.; Jakobsen, P.; Huusfeldt, P. O.; Begtrup, M. J. Org. Chem. 2000, 65, 9001-9006.

[7] Yadav, J. S.; Srinivas, Ch. Tetrahedron 2003, 59, 10325-10329.

[8] Williams, D. R.; Fromhold, M. G.; Earley, J. D. Org. Lett. 2001, 3, 2721-2724.

[9] Okawa, T.; Eguchi, S. Tetrahedron 1998, 54, 5853-5868.

[10] Nitta, M.; Iino, Y.; Mori, S. Tetrahedron Lett. 1991, 32, 67276730.

[11] Molina, P.; Díaz, I.; Tárraga, A. Tetrahedron 1995, 51, 5617-5630.

[12] Kamal, A.; Reddy, K. L.; Devaiah, V.; Shankaraiah, D. N. Synlett 2004, 2533-2536.

[13] O’Neil, I. A.; Murray, C. L.; Potter, A. J.; Kalindjian, S. B. Tetrahedron Lett. 1997, 38, 3609-3610.

[14] Pailer, M.; Haslinger, E. Monatsh. Chem. 1970, 101, 508-511.

[15] Sha, C.-K.; Chiu, R.-T.; Yang, C.-F.; Yao, N.-T., Tseng, W.-H.; Liao, F.-L.; Wang, S.-L. J. Am. Chem. Soc. 1997, 119, 4130-4135.

[16] Iino, Y.; Nitta, M. J. Chem. Soc., Perkin Trans 1 1994, 2579-2583.

[17] Nitta, M.; Iino, Y.; Kamata, K. J. Chem. Soc., Perkin Trans 1 1994, 2721-2725.

[18] Nitta, M.; Iino, Y.; Mori, S.; Takayasu, T. J. Chem. Soc., Perkin Trans 1 1995, 1001-1007.

[19] Snider, B. B.; Zhou, J. J. Org. Chem. 2005, 70, 1087-1088.

[20] Singh, P. N. D.; Klima, R. F.; Muthukrishnan, S.; Murthy, R. S.; Sankaranarayanan, J.; Stahlecker, H. M.; Patel, B.; Gudmundsdóttir, A. D. Tetrahedron Lett. 2005, 46, 4213-4217.

[21] Tingoli, M.; Tiecco, M.; Testaferri, L.; Andrenacci, R.; Balducci, R. J. Org. Chem. 1993, 58, 6097-6102.

[22] Honda, T.; Ishikawa, F.; Yamane, S.-I. J. Chem. Soc., Chem. Commun. 1994, 499-500.

[23] Okano, T.; Sakaida, T.; Eguchi, S. J. Org. Chem. 1996, 61, 88268830.

[24] De Kimpe, N.; Stevens, C. Tetrahedron 1995, 51, 2387-2402.

[25] Tárraga, A.; Molina, P.; López, J. L. Tetrahedron Lett. 2000, 41, 2479-2482.

[26] Purwono, B; Smalley, R. K.; Porter, T. C. Synlett 1992, 231-232.

[27] Jiang, B.; Yang, C.-G., Wang, J. J. Org. Chem. 2002, 67, 13961398.

[28] Jiang, B.; Yang, C.-G., Wang, J. J. Org. Chem. 2001, 66, 48654869.

[29] Nitta, M.; Ohnuma, M.; Iino, Y. J. Chem. Soc. Perkin Trans 1 1991, 1115-1118.
[30] Kanomata, N.; Kawaji, H.; Nitta, M. J. Org. Chem. 1992, 57, 618625.

[31] Ding, M.-W.; Fu, B.-Q.; Yuan, J.-Z. Heteroatom Chem. 2005, 16, 76-80.

[32] Williams, D. R.; Cortez, G. S. Tetrahedron Lett. 1998, 39, 26752678.

[33] Wang, J.; Sakamoto, S.; Kamada, K.; Nitta, A.; Noda, T.; Oguri, H.; Hirama, M. Synlett 2003, 891-893.

[34] Benalil, A.; Guerin, A.; Carboni, B.; Vaultier, M. J. Chem. Soc., Perkin Trans. 1 1993, 1061-1064.

[35] Anwar, B.; Grimsey, P.; Hemming, K.; Krajniewski, M.; Loukou, C. Tetrahedron Lett. 2000, 41, 10107-10110.

[36] Zhao, M.-X.; Wang, M.-X.; Yu, C.-Y.; Huang, Z.-T.; Fleet, G. W. J. J. Org. Chem. 2004, 69, 997-1000.

[37] Gelmi, M. L.; Pocar, D.; Viziano, M.; Destro, R.; Merati, F. J. Chem. Soc., Perkin Trans. 1 1992, 701-705.

[38] Eguchi, S.; Yamashita, K.; Matsushita, Y.; Kakehi, A. J. Org. Chem. 1995, 60, 4006-4012.

[39] Eguchi, S.; Yamashita, K.; Matsushita, Y. Synlett 1992, 295-296.

[40] Okawa, T.; Sugimori, T.; Eguchi, S.; Kakehi, A. Heterocycles 1998, 47, 375-382.

[41] Sugimori, T.; Okawa, T.; Eguchi, S.; Yashima, E.; Okamoto, Y. Chem. Lett. 1997, 869-870.

[42] Sugimori, T.; Okawa, T.; Eguchi, S.; Kakehi, A.; Yashima, E.; Okamoto, Y. Tetrahedron 1998, 54, 7997-8008.

[43] Okawa, T.; Eguchi, S. Tetrahedron Lett. 1996, 37, 81-84.

[44] Kurita, J.; Iwata. T.; Yasuike, S.; Tsuchiya, T. J. Chem. Soc., Chem. Commun. 1992, 81-82.

[45] O`Neil, I. A.; Murray, C. L.; Hunter, R. C.; Kalindjian, S. B.; Jenkins, T. C. Synlett 1997, 75-78.

[46] Gil, C.; Bräse, S. Chem. Eur. J. 2005, 11, 2680-2688.

[47] Goff, D. A.; Zuckermann, R. N. J. Org. Chem. 1995, 60, 57445745.

[48] Fuwa, H.; Okamura, Y.; Morohashi, Y.; Tomita, T.; Iwatsubo, T.; Kan, T.; Fukuyama, T.; Natsugari, H. Tetrahedron Lett. 2004, 45, 2323-2326.

[49] Kurosawa, W.; Kan, T.; Fukuyama, T. J. Am. Chem. Soc. 2003, $125,8112-8113$

[50] Kurosawa, W.; Kobayashi, H.; Kan, T.; Fukuyama, T. Tetrahedron 2004, 60, 9615-9628.

[51] Chen, J.; Forsyth, C. J. J. Am. Chem. Soc. 2003, 125, 8734-8735

[52] Chen, J.; Forsyth, C. J. Org. Lett. 2003, 5, 1281-1283.

[53] Fresneda, P. M.; Molina, P.; Delgado, S. Tetrahedron Lett. 1999, 40, 7275-7278.

[54] Fresneda, P. M.; Molina, P.; Delgado, S. Tetrahedron 2001, 57, 6197-6202.

[55] Molina, P.; Alías, A.; Balado, A.; Arques, A. Liebigs Ann. Chem. 1994, 745-749.

[56] Molina. P.; Conesa, C.; Velasco, M. D. Liebigs Ann./Recueil 1997, $107-110$.

[57] Molina, P.; Tárraga, A.; Curiel, D. Tetrahedron 1997, 53, 1589515902.

[58] Okawa, T.; Sugimori, T.; Eguchi, S.; Kakehi, A. Chem. Lett. 1996, 843-844.

[59] Alajarín, M.; Molina, P.; Vidal, A.; Tobar, F. Synlett 1998, 12881290.

[60] Eguchi, S.; Takeuchi, H.; Matsushita, Y. Heterocycles 1992, 33, 153-156.

[61] Eguchi, S.; Goto, S. Heterocyclic Commun. 1994, 1, 51-54.

[62] Snider, B. B.; Busuyek, M. V. Tetrahedron 2001, 57, 3301-3307.

[63] Eguchi, S.; Matsushita, Y.; Takeuchi, H. J. Org. Chem. 1992, 57, 6975-6979.

[64] Eguchi, S.; Suzuki, T.; Okawa, T.; Matsushita, Y.; Yashima, E.; Okamoto, Y. J. Org. Chem. 1996, 61, 7316-7319.

[65] Cledera, P.; Avendaño, C.; Menéndez, J. C. Tetrahedron 1998, 54, 12349-12360.

[66] Madrigal, A.; Grande, M.; Avendaño, C. Tetrahedron: Asymmetry 1998, 9, 3115-3123.

[67] Caballero, E.; Avendaño, C.; Menéndez, J. C. Tetrahedron: Asymmetry 1998, 9, 3025-3038.

[68] Cledera, P.; Avendaño, C.; Menéndez, J. C. J. Org. Chem. 2000, 65, 1743-1749. 
[69] Grieder, A.; Thomas, A. W. Synthesis 2003, 1707-1711.

[70] Bosch, I.; Romea, P.; Urpí, F.; Vilarrasa, J. Tetrahedron Lett. 1993, $34,4671-4674$.
[71] Hemming, K.; Loukou, C.; Elkatip, S.; Smalley, R. K. Synlett 2004, 101-105. 